\title{
Anandamide Signaling Augmentation Rescues Amygdala Synaptic Function and Comorbid Emotional Alterations in a Model of Epilepsy
}

\author{
${ }^{[}$Roberto Colangeli, ${ }^{1,2}{ }^{\circledR}$ Maria Morena, ${ }^{1,2}{ }^{\circledR}$ Quentin J. Pittman, ${ }^{1,3}$ Matthew N. Hill, ${ }^{1,2}$ and \\ G. Campbell Teskey ${ }^{1,2}$ \\ ${ }^{1}$ Hotchkiss Brain Institute, ${ }^{2}$ Department of Cell Biology and Anatomy, and ${ }^{3}$ Department of Physiology and Pharmacology, University of Calgary, \\ Calgary, Alberta T2N 4N1, Canada
}

Epilepsy is often associated with emotional disturbances and the endocannabinoid (eCB) system tunes synaptic transmission in brain regions regulating emotional behavior. Thus, persistent alteration of eCB signaling after repeated seizures may contribute to the development of epilepsy-related emotional disorders. Here we report that repeatedly eliciting seizures (kindling) in the amygdala caused a long-term increase in anxiety and impaired fear memory retention, which was paralleled by an imbalance in GABA/glutamate presynaptic activity and alteration of synaptic plasticity in the basolateral amygdala (BLA), in male rats. Anandamide (AEA) content was downregulated after repeated seizures, and pharmacological enhancement of AEA signaling rescued seizure-induced anxiety by restoring the tonic control of the eCB signaling over glutamatergic transmission. Moreover, AEA signaling augmentation also rescued the seizure-induced alterations of fear memory by restoring the phasic control of eCB signaling over GABAergic activity and plasticity in the BLA. These results indicate that modulation of AEA signaling represents a potential and promising target for the treatment of comorbid emotional dysfunction associated with epilepsy.

Key words: amygdala; anandamide; emotional behavior; epilepsy; FAAH; synaptic plasticity

Significance Statement

Epilepsy is a heterogeneous neurologic disorder commonly associated with comorbid emotional alterations. However, the management of epilepsy is usually restricted to the control of seizures. The endocannabinoid (eCB) system, particularly anandamide (AEA) signaling, controls neuronal excitability and seizure expression and regulates emotional behavior. We found that repeated seizures cause an allostatic maladaptation of AEA signaling in the amygdala that drives emotional alterations. Boosting AEA signaling through inhibition of its degradative enzyme, fatty acid amide hydrolase (FAAH), restored both synaptic and behavioral alterations. FAAH inhibitors dampen seizure activity in animal models and are used in clinical studies to treat the negative consequences associated with stress. Thereby, they are accessible and can be clinically evaluated to treat both seizures and comorbid conditions associated with epilepsy.

\section{Introduction}

Comorbid psychiatric disorders are common in people with epilepsy (Kanner, 2016). These comorbidities include depression, anxiety disorders, and memory disturbances, which profoundly impact quality of life (Kanner et al., 2010). Temporal lobe epilepsy (TLE), the most common form of focal epilepsy in people,

\footnotetext{
Received Jan. 9, 2020; revised May 14, 2020; accepted June 21, 2020.

Author contributions: R.C. and G.C.T. designed research; R.C., M.M., and M.N.H. performed research; R.C. and M.M. analyzed data; R.C. wrote the paper; Q.J.P., M.N.H., and G.C.T. edited the paper.

This work was supported by Canadian Institutes for Health Research (CIHR) Grants PJT-162204 and FRN162177 (to G.C.T. and M.N.H.) and PJT-159454 (to Q.J.P.). R.C. received salary support from an Eyes High postdoctoral fellowship. M.M. received salary support from Alberta Innovates and CIHR postdoctoral fellowships.

The authors declare no competing financial interests.

Correspondence should be addressed to Roberto Colangeli at roberto.colangeli@ucalgary.ca.

https://doi.org/10.1523/JNEUROSCI.0068-20.2020

Copyright $\odot 2020$ the authors
}

is characterized by recurrent self-generated discharges arising from temporal regions and is frequently associated with interictal behavioral dysfunction (Kanner, 2016). The most commonly prescribed antiepileptic drugs reduce seizure frequency or severity but have no effect, or may even exacerbate emotional and memory disturbances (Eddy et al., 2011).

The amygdala is a key brain structure involved in ascribing emotional valence to external stimuli (LeDoux, 2000), and it also generates and propagates seizure activity (Aroniadou-Anderjaska et al., 2008). Preclinical studies have shown alterations of emotional behavior following repeatedly elicited amygdala seizures (Botterill et al., 2014; Chen et al., 2016). The endocannabinoid (eCB) system is a neuromodulatory system in the brain that finely shapes neuronal excitability and synaptic plasticity (Chevaleyre et al., 2006; Kano et al., 2009). The eCB system is strongly activated during seizures (Stella et al., 1997), and both exogenous and endogenous 
cannabinoids acutely dampen neuronal hyperexcitability and seizure expression (Marsicano et al., 2003; Wallace et al., 2003; Colangeli et al., 2017, 2019). The eCB system consists of the cannabinoid type 1 (CB1) and cannabinoid type 2 (CB2) receptors, the two main endogenous cannabinoids anandamide (AEA) and 2arachidonoylglycerol (2-AG) as well as the enzymes responsible for their synthesis and degradation (Kano et al., 2009). Alterations of the eCB molecular elements have been reported in brains of both animal models of epilepsy and people with TLE (Ludányi et al., 2008; Di Maio et al., 2019), and reduced levels of AEA have been observed in the cerebrospinal fluid of people with TLE (Romigi et al., 2010). Moreover, enhancement of AEA signaling restores seizure-induced impairment of short and long-term synaptic plasticity in the dentate gyrus after perforant path kindling in rats (Colangeli et al., 2017).

$\mathrm{eCB}$ signaling is as an important regulator of anxiety-like behavior and fear memory in rodents (Bedse et al., 2014; Morena et al., 2016a). Impairment of eCB signaling in the amygdala induces anxiety-like behavior (Haller et al., 2004) and causes alterations of fear memory dynamics in rodents (Marsicano et al., 2002). Therefore, we tested the hypothesis that repeated amygdala seizures caused dysfunction of emotional behavior through persistent maladaptive alteration of $\mathrm{eCB}$ signaling in the basolateral amygdala (BLA).

\section{Materials and Methods}

\section{Animals}

Male Hooded Long-Evans (LE) rats (300-350 g; Charles River) at the start of behavioral or electrophysiological experiments were housed individually in a temperature-controlled $\left(23 \pm 1^{\circ} \mathrm{C}\right)$ vivarium room and maintained under specified pathogen free conditions and a 12/12 h light/dark cycle (7:00 A.M. to 7:00 P.M. lights on). Food and water were available ad libitum. All tests were performed during the light phase of the cycle. All experimental procedures were in compliance with protocols approved by the University of Calgary Animal Care Committee and guidelines from the Canadian Council on Animal Care. All efforts were made to minimize animal suffering and to reduce the number of animals used.

\section{Surgery}

Chronically implanted electrodes for the kindling procedure were constructed from Teflon-coated, stainless steel wire, $178 \mu \mathrm{m}$ in diameter (A-M Systems). Wire ends were stripped of Teflon and connected to gold-plated male amphenol pins. Rats (both sham and kindled) were anaesthetized with a $5 \%$ isoflurane and maintained between $1 \%$ and $2 \%$. Animals were then positioned in a stereotaxic frame (David Kopf Instruments), and one bipolar electrode was chronically implanted into the right BLA (coordinates: anteroposterior, $-2.8 \mathrm{~mm}$, and mediolateral, $-4.8 \mathrm{~mm}$ from bregma; dorsoventral, $-8.0 \mathrm{~mm}$ from dura). The electrodes were anchored to the skull using dental cement and three stainless steel screws. One of the three screws served as a ground electrode. Rats were given buprenorphine and allowed to recover from surgery for one week before the starting of kindling procedures.

\section{Drugs}

The AEA hydrolysis inhibitor URB597 (0.5 mg/kg; Cayman Chemical), or its vehicle (5\% polyethylene glycol, $5 \%$ Tween 80 , and $90 \%$ saline) were injected intraperitoneally $(2 \mathrm{ml} / \mathrm{kg}), 60 \mathrm{~min}$ before the elevated plus maze (EPM) experiment, or immediately after the fear conditioning session, or $60 \mathrm{~min}$ before slicing preparation for electrophysiology experiments. The dose was chosen based on previous published papers (Kathuria et al., 2003) and on pilot experiments performed in our laboratory. All drug solutions were freshly prepared before each experiment.

\section{Experimental design and procedure}

Kindling procedure

The kindling procedure consisted of a total of 20 electrical stimulations of the right amygdala (1 ms, biphasic square-wave pulses, $60 \mathrm{~Hz}$ for 1-s) with a stimulation current $20 \%$ above the initial afterdischarge threshold (Farrell et al., 2016). Electrical stimulation was delivered twice daily over a period of $10 \mathrm{~d}$ with a gap of at least $4 \mathrm{~h}$ between stimulations to allow postictal effects to dissipate (Farrell et al., 2016, 2017). Similarly to kindled rats, sham animals were placed in the kindling cage twice daily for $10 \mathrm{~d}$ and connected to the stimulator, but no current was delivered. The behavioral convulsion elicited by each stimulation was scored using a Racine's scale (Racine, 1972). The classes were operationally defined as class 1: immobility; class 2: orofacial automatisms with head nodding; class 3: unilateral forelimb clonus; class 4: rearing with bilateral forelimb clonus; and class 5: rearing with bilateral forelimb clonus followed by falling. Using this classification system, rats are considered to be "kindled" after three consecutive class 5 convulsions (Pinel and Rovner, 1978).

\section{$E P M$}

One week after the last kindling session, rats were tested for anxiety-like behavior in an EPM. Before EPM testing, animals were handled for $1 \mathrm{~min}$ each for three consecutive days. To habituate the animals to the behavioral testing room, rats were transferred to the behavioral room, and their home cages were placed in sound attenuating, ventilated, and lighted cabinets for at least $30 \mathrm{~min}$ before and after the handling and for 90 min before EPM testing. The EPM apparatus (Med Associates Inc.) comprised two open arms $\left(50 \times 10 \times 75 \mathrm{~cm}^{3}\right)$ and two closed arms $\left(50 \times 10 \times 75 \mathrm{~cm}^{3}\right)$ that extended from a common central platform $\left(10 \times 10 \mathrm{~cm}^{2}\right)$. The maze was located within a sound-isolated room under red light conditions (open arms, 15 lux; closed arms, 5 lux). A slightly modified procedure of that we previously described (Morena et al., 2016b, 2019) was used. Each rat was placed in the central area of the apparatus with the head facing a closed arm. Exposure lasted for $5 \mathrm{~min}$, and the behavior was recorded by using a video camera positioned above the experimental apparatus and analyzed using the software Noldus EthoVision XT (RRID: SCR_000441). The following parameters were analyzed as indicators of anxiety-like behavior and locomotor activity: percent time spent in the open arms (time open \%), expressed as [(seconds spent on the open arms of the maze/seconds spent on the open + closed arms) $\times 100$ ]; percent open arm entries (open entries \%), expressed as [(number of entries into the open arms/number of entries into open + closed arms) $\times 100$ ]; total distance traveled, expressed in centimeters (distance). The maze was cleaned with $70 \%$ ethanol solution after each use.

\section{Auditory fear conditioning}

One week after the last kindling session, separate cohorts of animals were used for the auditory fear conditioning experiments, by using a slightly modified procedure of that previously described (Morena et al., 2019). To habituate the animals to the behavioral testing room, rats were transferred to the behavioral room and their home cages were placed in sound attenuating, ventilated, and lighted cabinets for at least $30 \mathrm{~min}$ before and after the handling on days 1 and 2, and for $90 \mathrm{~min}$ before and after testing, the following days. Rats were handled for $1 \mathrm{~min}$ each. On days 1 and 2, immediately after the handling procedure animals were habituated to the fear-conditioning chambers (context A, day 1 and context B, day 2) for $10 \mathrm{~min}$. Auditory fear conditioning (day 3), was performed in context A. After a 5-min acclimation period, all rats were exposed to three conditioning trials. Each conditioning trial involved presentation of the conditioned stimulus (CS; $80 \mathrm{~dB}, 4-\mathrm{Hz}$ tone) for $30 \mathrm{~s}$, co-terminating with a 1-s unconditioned stimulus (US; $0.90-\mathrm{mA}$ footshock). Intertrial interval (ITI) between two consecutive CS-US pairings was $3 \mathrm{~min}$. After conditioning, each rat was returned to its home cage. On day 4, rats received a 24-h memory retention session consisting of 18 CS presentations with an ITI between CSs of $2 \mathrm{~min}$, in context B. On day 5 , rats received a $48-\mathrm{h}$ memory retention session in context $\mathrm{B}$, consisting of 5 CSs $(2$-min ITI). The fear conditioning chambers $(30.5 \times 24.1 \times$ $21 \mathrm{~cm}^{3}$ ) were equipped with metal stainless-steel rod flooring connected 
to a shock generator. Each chamber was enclosed within ventilated and sound attenuating cubicles (Med Associates Inc.). Two different contexts were used (contexts A and B). Context A consisted of a chamber with a grid floor, back and side metal walls, clear Plexiglas front door and ceiling, and white light. Context A was cleaned with $70 \%$ ethanol between rats. To create a novel testing context (context B), the original grid floor was covered by a white opaque plastic insert, and the side metal walls were covered by a white plastic panel to create a curved wall. Context B was cleaned with Virkon solution between rats. A video camera, located on the inner door of the conditioning box, recorded video, and the resulting output was analyzed for freezing behavior (i.e., absence of movement except for respiration) using Video Freeze software (Med Associates Inc.; RRID: SCR_014574).

\section{Electrophysiology}

One week after the last evoked seizure rats were decapitated under deep anesthesia with isoflurane and transcardially perfused with ice cold slicing solution containing the following: $87 \mathrm{~mm} \mathrm{NaCl}, 2.5 \mathrm{~mm} \mathrm{KCl}, 25 \mathrm{~mm}$ $\mathrm{NaHCO}_{3}, 0.5 \mathrm{~mm} \mathrm{CaCl}_{2}, 7 \mathrm{~mm} \mathrm{MgCl}_{2}, 1.25 \mathrm{~mm} \mathrm{NaH}_{2} \mathrm{PO}_{4}, 25 \mathrm{~mm}$ D-glucose, and $75 \mathrm{~mm}$ sucrose. Coronal brain slices of the BLA $(300 \mu \mathrm{m}$ in thickness) were prepared with Leica VT1000S slicer (RRID: SCR_ 016495) in ice-cold slicing solution. For recovery, slices were incubated in a holding chamber with normal artificial CSF (ACSF) containing the following: $126 \mathrm{~mm} \mathrm{NaCl}, 2.5 \mathrm{~mm} \mathrm{KCl}, 2.5 \mathrm{mM} \mathrm{CaCl}_{2}, 1 \mathrm{mM} \mathrm{MgSO}_{4}, 1.25$ $\mathrm{mm} \mathrm{NaH}_{2} \mathrm{PO}_{4}, 26 \mathrm{~mm} \mathrm{NaHCO}_{3}$, and $10 \mathrm{~mm}$ glucose at $\mathrm{pH} 7.4$ for $30 \mathrm{~min}$ at $32^{\circ} \mathrm{C}$, and after that at room temperature for at least $30 \mathrm{~min}$. After incubation, the slices were placed in the recording chamber and perfused with ACSF at a flow rate of $1.5 \mathrm{ml} / \mathrm{min}$. Only the left side of the BLA, contralateral to the implantation side, was used in all the electrophysiological experiments. All experiments were performed at room temperature $\left(22-25^{\circ} \mathrm{C}\right)$. For whole-cell patch-clamp recordings, principal neurons of the BLA were distinguished from interneurons according to their morphologic and electrophysiological properties (Washburn and Moises, 1992). Basic intrinsic properties, EPSC recordings and inhibitory/excitatory (I-E) ratio experiments were performed with borosilicate glass electrodes (4-6 M $\Omega$ ) filled with the standard intracellular solution with the following composition: $108 \mathrm{~mm}$ K-gluconate, $8 \mathrm{~mm} \mathrm{Na}$-gluconate, $2 \mathrm{~mm} \mathrm{MgCl}_{2}$, $8 \mathrm{~mm} \mathrm{KCl}, 4 \mathrm{~mm}$ K2-ATP, $0.3 \mathrm{~mm} \mathrm{Na-GTP,} 1 \mathrm{~mm}$ EGTA, and $10 \mathrm{~mm}$ HEPES, pH 7.4 adjusted with KOH. GABA-A receptor-mediated IPSCs were recorded by using glass electrodes (3-5 $\mathrm{M} \Omega$ ) filled with a solution containing the following: $90 \mathrm{mM} \mathrm{CsCH}_{3} \mathrm{SO}_{3}, 50 \mathrm{~mm}$ CsCl, 1 mm EGTA, 10 mM HEPES, $4.6 \mathrm{~mm} \mathrm{MgCl}, 0.1 \mathrm{~mm} \mathrm{CaCl}_{2}, 5 \mathrm{~mm}$ QX314, $0.3 \mathrm{~mm} \mathrm{Na-GTP,} \mathrm{and} 4 \mathrm{~mm}$ Mg-ATP, pH 7.3 adjusted with CsOH. $40 \mu \mathrm{M}$ D-(-)-2-amino-5-phosphono-pentanoic acid (D-AP-5) and $20 \mu \mathrm{M}$ 6,7-dinitroquinoxaline-2,3-dione disodium (DNQX) were added to the bath to block glutamatergic transmission. In the I-E experiments, IPSCs were recorded by using standard intracellular solution allowing both positively directed IPSCs and negative going EPSCs to be recorded in the same cell during the same experiment where we could not pharmacologically isolate glutamate or GABA transmissions. The amplitudes and frequencies of spontaneous IPSCs (sIPSCs) and spontaneous EPSCs (sEPSCs) were detected by continuous recording over 300 s by using Mini Analysis 6.0.7 software (Synaptosoft), using thresholds five times the root mean square of noise levels. Neurons were held at $-60 \mathrm{mV}$ to record EPSC and $-70 \mathrm{mV}$ to record IPSC. For the I-E paradigm evoked PSCs (ePSCs) were evoked in voltage clamp mode by varying the membrane potential of the recorded neuron to isolate currents associated with glutamatergic or GABAergic currents. eEPSCs were recorded by clamping the voltage of a cell at $-60 \mathrm{mV}$ where the driving force for the inhibitory component is effectively eliminated leaving only excitatory currents. Outward eIPSCs were recorded with the same stimulation setting as for eEPSCs by clamping the voltage of the cell to $0 \mathrm{mV}$ where the contribution of AMPA-mediated PSCs is negligible. Comparison of the respective currents at each of these potentials (eIPSCS/eEPSC amplitude ratio) was then calculated and analyzed. All the experiments were performed with the continuous presence of AP-5 to the bath to block NMDA-mediated currents. Cell capacitance and access resistance (initial value $<25 \mathrm{M} \Omega$ ) were monitored during experiments, and recordings were accepted for analysis if either variable did not change by $>20 \%$. Extracellular field potential recordings were performed using glass microelectrodes (1-2 M $\Omega$ ) filled with ACSF. To stimulate putative glutamatergic or GABAergic fibers, monopolar ACSFfilled patch-type pipettes $(1 \mathrm{M} \Omega)$ placed within the BLA just medial to the external capsule were used. Long-term depression of inhibitory transmission (iLTD) was induced by delivering inhibitory low frequency stimulation (iLFS) composed of 100 stimuli at $1 \mathrm{~Hz}$ through the stimulating electrode. For high-frequency stimulation (HFS), four trains of 100 pulses with $100 \mathrm{~Hz}$ and an interstimulus interval of $20 \mathrm{~s}$ were applied in the lateral amygdala (LA). For extracellular field potential recordings, the stimulus intensities were adjusted to produce half-maximal responses. Signals were collected via an Axopatch 200B amplifier (Molecular Devices). The pCLAMP 9 software (Molecular Devices) was used for data acquisition. The signals were filtered at $1 \mathrm{kHz}$ and digitized at $10 \mathrm{kHz}$.

\section{eCB extraction and analysis}

One week after the last evoked seizure, sham and kindled rats were killed by rapid decapitation. Both the right and left amygdalae were rapidly dissected and stored at $-80^{\circ} \mathrm{C}$. The lipid extraction process was conducted as previously described (Morena et al., 2015; Qi et al., 2015). Brain tissue was weighed and placed into borosilicate glass culture tubes containing 2 $\mathrm{ml}$ of acetonitrile $(\mathrm{ACN})$ with $5 \mathrm{pmol}$ of [2H8]AEA and $5 \mathrm{nmol}$ of [2H8] 2 -AG for extraction, and homogenized with a glass rod. Tissue was sonicated for $30 \mathrm{~min}$ on ice water and incubated overnight at $-20^{\circ} \mathrm{C}$ to precipitate proteins, then centrifuged at $1500 \times g$ to remove particulates. The supernatants were transferred to a new glass tube and evaporated to dryness under $\mathrm{N}_{2}$ gas. The samples were reconstituted in $300 \mu$ of ACN and dried again under $\mathrm{N}_{2}$ gas. Lipid extracts were suspended in $20 \mu \mathrm{l}$ of $\mathrm{ACN}$ and stored at $-80^{\circ} \mathrm{C}$ until analysis. Analysis of AEA and 2-AG was performed by liquid chromatography tandem mass spectrometry (LC-MS/MS) analysis as previously detailed (Qi et al., 2015).

\section{Statistical analysis}

Data were analyzed using GraphPad Prism 6 (RRID: SCR_002798). Differences between groups were analyzed using Student's $t$ test for unpaired data, two-way or repeated measures (RM) ANOVA followed by Tukey's post hoc test for multiple comparisons when appropriate. Significance was accepted at $p<0.05$. Statistical design for each experiment is detailed in the corresponding figure legend.

\section{Results}

\section{Repeated amygdala seizures induce persistent interictal increase of anxiety-like behavior and impairment of fear memory retention}

Kindling models the pathophysiology of TLE and the aberrant neural plasticity that promotes interictal emotional and cognitive comorbidities (Teskey and Corcoran, 2009, 2015). Here, to test whether amygdala kindling persistently alters emotionality, we elicited twenty electrically evoked electrographic seizures over two weeks, and then we assessed emotional behaviors in rats that have been seizure-free for one week to allow postictal effects to dissipate. In this study, all rats subjected to kindling showed at least three consecutive stage five behavioral seizures at the end of the twenty amygdala stimulations (data not shown). We assessed anxiety-like behavior in sham or kindled rats by using the EPM (Fig. 1A) wherein decreased time spent in EPM open arms is interpreted as increased anxiety. The effect of amygdala kindling on anxiety-like behavior has previously yielded mixed results since both anxiolytic and anxiogenic effects of kindled seizures have been reported (Helfer et al., 1996; Adamec et al., 2004; Hannesson et al., 2008; Chen et al., 2016). Here, we found that rats subjected to amygdala kindling showed significantly reduced percentage of time spent in open arms (Fig. 1B) and open arm entries (Fig. 1C) with respect to the sham control group, indicating an increased anxiety-like behavior. These effects were not due to changes in motor activity because kindling did not affect 


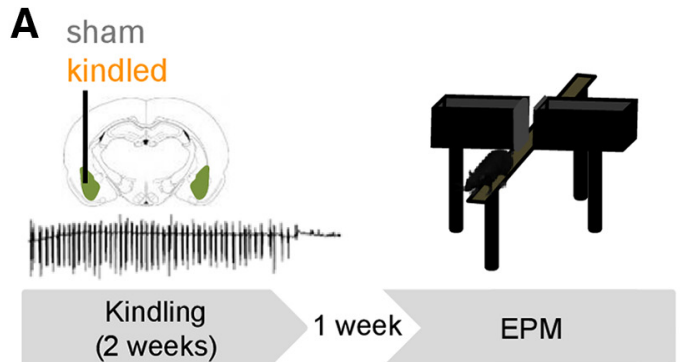

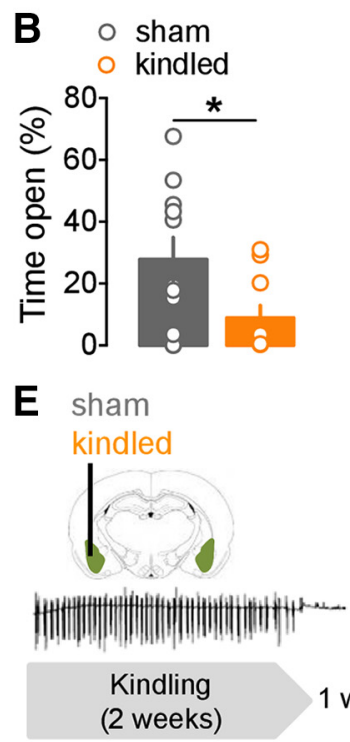

$\mathbf{F}$

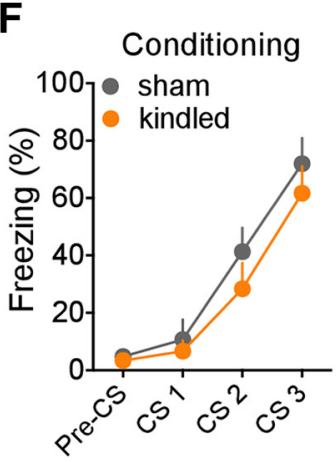

C

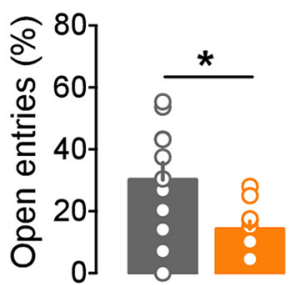

D

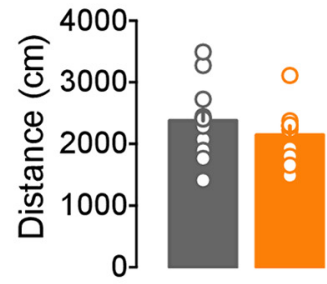

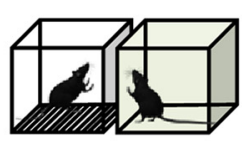

Days 1-2

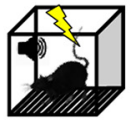

Day 3

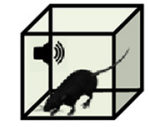

Day 4

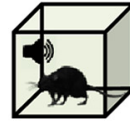

Day 5

$24 \mathrm{~h}$ fear memory $48 \mathrm{~h}$ fear memory retention retention

\section{G}

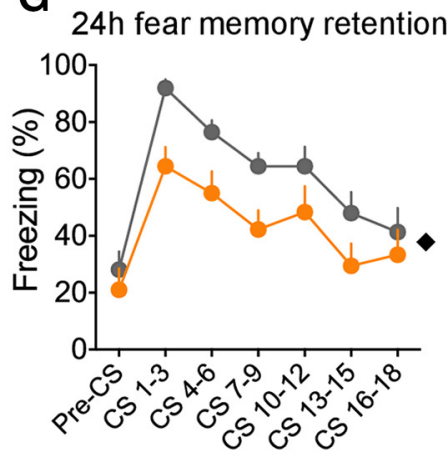

Figure 1. Kindled rats present an anxiety-like phenotype with impaired fear memory retention. Schematic representation of the experimental design for the assessment of seizure-induced effect on anxiety-like behavior $(\boldsymbol{A})$. Amygdala kindling increased indices of anxiety-like behavior on the EPM $(\boldsymbol{B}-\boldsymbol{D})$. Effects of repeated amygdala seizures on percentage time spent in the open arms ( $\boldsymbol{B}$, unpaired $t$ test: $\left.t_{(19)}=2.28, p=0.034\right)$, open arm entries $\left(\boldsymbol{C}\right.$, unpaired $t$ test: $\left.t_{(19)}=2.52, p=0.021\right)$, and total distance traveled $\left(\boldsymbol{D}\right.$, unpaired $t$ test: $\left.t_{(19)}=0.97, p=0.34\right)$. Schematic representation of the experimental design for the assessment of seizure-induced effect on fear memory dynamics $(\boldsymbol{E})$. Repeated amygdala seizures reduced fear expression 24 and $48 \mathrm{~h}$ after conditioning $(\boldsymbol{F}-\boldsymbol{H})$. Percentage freezing during cued fear conditioning $\left(\boldsymbol{F}\right.$, two-way RM ANOVA, seizures effect: $F_{(1,25)}=1.32, p=0.26$; $\left(S-U S\right.$ effect: $F_{(3,75)}=41.15, p<0.0001$; interaction: $\left.F_{(3,75)}=0.36, p=0.78\right)$, 24-h fear memory retention $\left(G\right.$, two-way RM ANOVA, seizures effect: $F_{(1,25)}=7.22, p=0.013$; $C S$ effect: $F_{(6,150)}=21.43, p<0.0001$; interaction: $F_{(6,150)}=0.90$, $p=0.50)$ and 48-h fear memory retention $\left(\boldsymbol{H}\right.$, two-way RM ANOVA, seizures effect: $F_{(1,25)}=7.45, p=0.011$; CS effect: $F_{(2,50)}=42.35, p<0.0001$; interaction: $\left.F_{(2,50)}=3.06, p=0.056\right)$. Data are expressed as mean \pm SEM ${ }^{*} p<0.05 ; p<0.05$ indicates main effect of seizures; $n=10-15$ per group.

the total distance traveled during the 5-min task (Fig. 1D). We then tested fear memory dynamics in a different set of rats. Unlike anxiety-like behavior, the interictal consequences of kindling on fear memory has received much less experimentation. It has previously been shown that kindling of the BLA impairs the retrieval of conditioned fear memories (Fournier et al., 2013; Botterill et al., 2014). However, in these studies, behavioral assessments were performed $1 \mathrm{~d}$ after the final kindling stimulation when the postictal state might still affect behavioral responses. Moreover, authors performed a form of long-term kindling consisting of 99 stimulations. Here, we tested sham and kindled rats by using the classic auditory fear conditioning paradigm (Fig. $1 E$ ) one week after the last of the twenty evoked seizures. In this task, animals learn to associate a CS, a tone, with an US, an electric footshock, and subsequent re-exposure to the tone leads to fear responses, which include freezing behavior. We found that kindling did not alter the acquisition of fear response since CS-US-evoked freezing during conditioning revealed a significant CS-US presentation effect over time in both groups but no difference between groups (Fig. $1 F$ ), indicating that all rats acquired CS-evoked fear responses. However, kindling significantly impaired learned fear expression and fear memory 
retrieval as kindled rats presented decreased mean freezing throughout the CS presentations when tested both $24 \mathrm{~h}$ (Fig. 1G) and $48 \mathrm{~h}$ after conditioning (Fig. $1 H$ ) compared with the sham group.

\section{Repeated amygdala seizures do not alter membrane properties and intrinsic excitability but do alter synaptic activity of BLA pyramidal neurons}

We then determined the electrophysiological basis of interictal alterations of emotional behavior by performing whole-cell patch-clamp recordings in BLA pyramidal neurons one week after the last evoked seizure (Fig. 2A). We first examined intrinsic properties of BLA pyramidal neurons (Fig. $2 B$ ) and found that all recorded pyramidal neurons in both groups showed similar membrane profiles in response to a series of current steps (Fig. $2 B$ ) as shown in the current-voltage ( $\mathrm{I}-\mathrm{V}$ ) plots (Fig. $2 \mathrm{C}$ ). The resting membrane potentials (Fig. 2D), the action potential threshold (Fig. 2E), the minimal current necessary to evoke action potential firing (rheobase; Fig. $2 F$ ) and the number of action potentials in response to current steps (Fig. $2 G$ ) were similar between kindled and sham rats. Thus, basic intrinsic properties of BLA neurons were not altered by repeated seizure activity in agreement with a previous report (Shoji et al., 1998).

We then hypothesized that, despite the intrinsic excitability of BLA pyramidal neurons being unaltered in kindled rats, AMPA receptor-mediated sEPSCs (Fig. $2 \mathrm{H}$ ) onto BLA pyramidal neurons would be affected by repeated seizure activity. We observed that the frequency of sEPSCs is significantly increased in the kindled group compared with the sham group (Fig. $2 H$ ). Since we did not find any difference in the amplitude of sEPSCs between groups (Fig. $2 \mathrm{H}$ ), we hypothesized that kindlinginduced alteration of excitatory synaptic activity might be due to a presynaptic response. To test this hypothesis, we measured eEPSCs in response to paired stimulation with an interstimulus interval of $50 \mathrm{~ms}$ (Fig. 2I). As previously reported (Acharjee et al., 2018), paired stimulations in sham rats evoked eEPSC responses with similar amplitude (Fig. 2I). Conversely, kindled rats had a reduced paired pulse ratio with the second eEPSC response significantly smaller than the first (Fig. 2I), and, together with the findings for increased sEPSC frequency, but not amplitude, this is consistent with an increased probability of neurotransmitter release by presynaptic glutamatergic terminals onto the BLA in kindled rats. Pyramidal neurons are also under a pronounced tonic inhibitory control by GABAergic inhibitory circuits, prompting us to determine how sIPSCs (Fig. 2J) are affected by repeated seizure activity. We observed reduced frequency, but not amplitude of sIPSCs (Fig. 2J), in the kindled group which was paralleled with an increased GABAergic paired pulse ratio (Fig. $2 \mathrm{~K}$ ), suggesting that repeated seizure activity caused decreased probability of GABA release from GABAergic terminals targeting BLA principal neurons.

\section{Repeated amygdala seizures downregulate AEA content in the BLA and systemically boosting AEA signaling rescues seizure-induced emotional dysfunction}

It is well established that the eCB signaling plays an important role in the modulation of emotional behavior by its tight control of presynaptic neurotransmitter release in the BLA (Morena et al., 2016a). Thus, we asked whether repeated seizures persistently altered the levels of the two main eCB ligands in the amygdala (Fig. 3A). One week after the last evoked seizure AEA levels were significantly lower in the kindling group when compared with the sham group while 2-AG content was unaltered (Fig. $3 B, C$ ).
This raised the question as to whether the reduced levels of AEA were causal in altering behavior. Thus, we attempted to restore repeated seizure-induced alteration of emotional behavior by boosting AEA signaling through inhibition of its catabolic enzyme fatty acid amide hydrolase (FAAH; Kathuria et al., 2003). In the first experiment, we treated kindled and sham rats with a systemic administration of either the FAAH inhibitor URB597 $(0.5 \mathrm{mg} / \mathrm{kg})$ or its vehicle $1 \mathrm{~h}$ before testing on the EPM (Fig. 4A). We again observed that repeated seizures increased anxiety-like behavior as the kindled group treated with vehicle spent significantly less time in the open arms (Fig. 4B) and performed significantly fewer entries in the open arms (Fig. 4C) compared with the sham/vehicle group. AEA augmentation completely rescued these alterations. Indeed, kindled rats administered URB597 had percentages of time spent in open arms (Fig. $4 B$ ) and open arm entries (Fig. 4C) equivalent to those of sham rats administered either vehicle or URB597. Furthermore, neither amygdala seizures nor drug treatment altered rats' locomotor activity (Fig. 4D). We then asked whether AEA augmentation was also able to rescue impairment of fear memory retention in kindled rats (Fig. 4E). One week after the last evoked sham or kindled seizure, drug-free rats of both groups were trained to associate a neutral stimulus with a footshock during the conditioning session (Fig. 4E). At the end of the conditioning session, we treated sham and kindled rats with either vehicle or URB597 $(0.5 \mathrm{mg} / \mathrm{kg})$, and, after the treatment, we placed rats back in their home cage. We choose to inject rats immediately after the conditioning to boost AEA signaling during the consolidation phase of fear memory based on previous findings showing that eCBs, particularly AEA, modulate emotional memory consolidation (Morena et al., 2014, 2019). As shown in Figure 4F, during conditioning, there were no preexisting differences in freezing among rats before drug treatment. Kindled rats treated with vehicle showed impaired fear memory retention at both $24 \mathrm{~h}$ (Fig. $4 G$ ) and $48 \mathrm{~h}$ (Fig. $4 H$ ) after the conditioning as we observed in this group a decreased mean freezing throughout all the CS presentations when compared with the sham group treated with vehicle. URB597 rescued fear memory alterations in the kindled group as we no longer observed a difference in mean freezing during CS presentations among sham/vehicle, sham/URB and kindled/URB groups at both 24 and $48 \mathrm{~h}$ after the conditioning session (Fig. 4G,H).

\section{Systemically boosting AEA signaling restores repeated seizure-induced alteration of glutamatergic, but not} GABAergic transmission, and re-establishes the I-E balance in the BLA

Lower AEA levels were associated with dysfunction in anxietylike behavior and boosting AEA signaling with URB597 reversed those alterations. We then attempted to reverse the seizureinduced changes in synaptic physiology using the same approach. In order to keep a consistent experimental protocol with the behavioral tests, we performed in vivo administration of either URB597 $(0.5 \mathrm{mg} / \mathrm{kg})$ or vehicle and then, $1 \mathrm{~h}$ after the injection, proceeded with the killing and collection of brain slices for electrophysiological experiments. Since both glutamatergic and GABAergic transmission are under control of the eCB system (Yoshida et al., 2011; Hill and Tasker, 2012), we investigated the effect of a systemic administration of either URB597 or its vehicle on both sEPSCs and sIPSCs recorded in BLA pyramidal neurons in kindled and sham groups. No significant difference in either the mean frequency or amplitude of sEPSCs of BLA pyramidal neurons recorded from sham rats pretreated with 
A

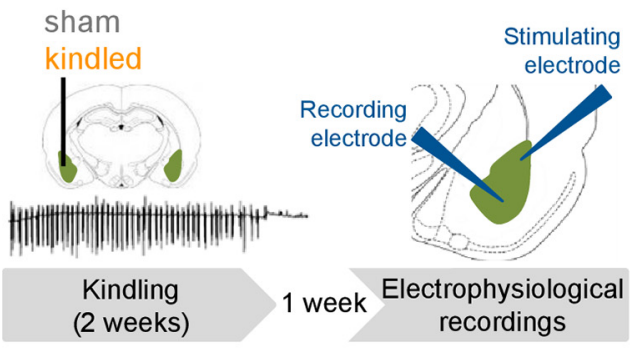

O sham $\bigcirc$ kindled

B

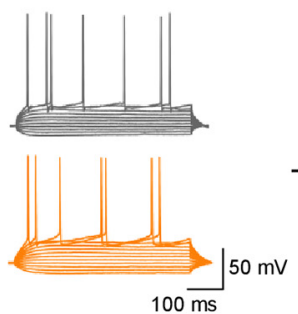

E

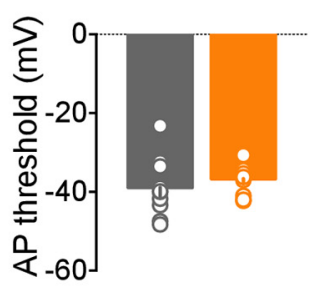

C

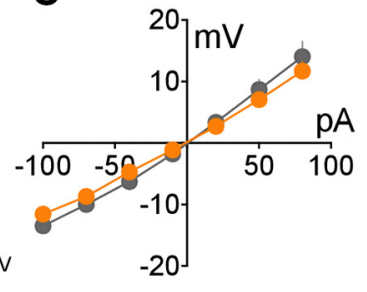

F

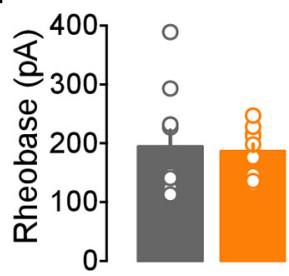

H
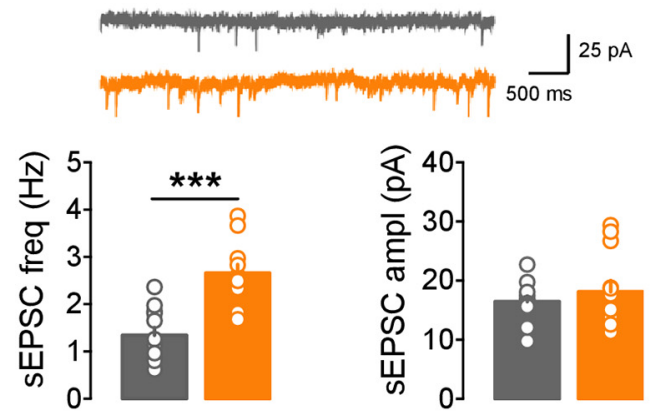

J
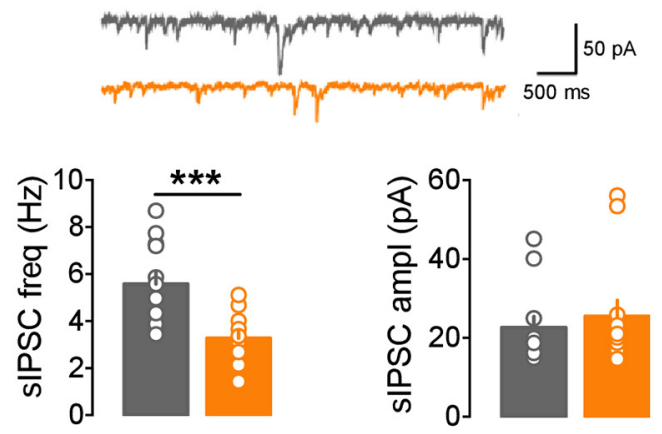

D

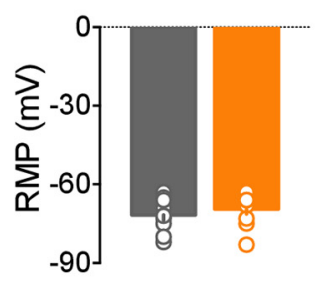

G

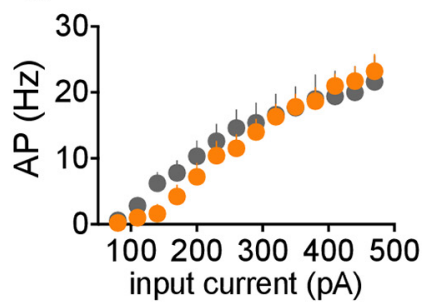

I
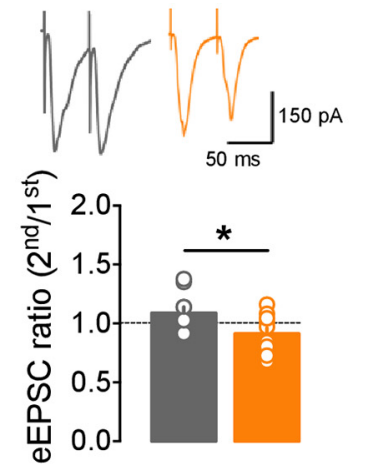

K

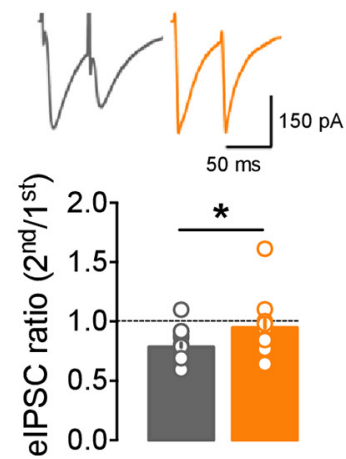

Figure 2. Repeated amygdala seizures alter synaptic activity without affecting intrinsic properties of BLA pyramidal neurons. Schematic representation of the experimental design for the assessment of repeated seizure-induced effect on electrophysiological properties of BLA pyramidal neurons $(\boldsymbol{A})$. Typical membrane responses to somatic current steps of sham (above) and kindled (below) BLA pyramidal neurons $(\boldsymbol{B})$. I-V curves showing no difference between sham $(n=10$ cells, 9 rats) and kindled ( $n=10$ cells, 10 rats) groups (two-way RM ANOVA with current $F_{(6,108)}=81.26, p<0.0001$ and seizures $F_{(1,18)}=0.16, p=0.69$ as factors; interaction: $F_{(6,108)}=0.67, p=0.68$; $)$. The resting membrane potential (sham: $-71.7 \pm 1.97, n=10$ cells, 9 rats vs kindled: $-69.40 \pm 1.89 \mathrm{mV}, n=10$ cells, 10 rats; $\boldsymbol{D}$ ), the action potential threshold (sham: $-38.90 \pm 2.38 \mathrm{mV}, n=10,9$ vs kindled: $-36.67 \pm 1.24 \mathrm{mV}, n=10,10 ; E$ ), and rheobase (sham: $194.0 \pm 28.59 \mathrm{pA}, n=10,9$ vs kindled: $186.2 \pm 12.75 \mathrm{pA}, n=10,10 ; \boldsymbol{F}$ ) were similar in both groups; $p>0.05$, Student's $t$ test. $\mathbf{G}$, Summary of current-firing curves indicating that the number of evoked action potentials in response to somatic

URB597 when compared with sham rats pretreated with vehicle were found (Fig. $5 A-C)$. However, we did find that URB597 produced a significant reduction in sEPSC rate in the kindled rats when compared with the kindled group injected with vehicle (Fig. $5 B$ ), such that there was no difference between sham and kindled rats after URB597 administration. Thus, systemic augmentation of AEA signaling does not alter glutamate release within the BLA per se but is able to dampen seizureinduced increased glutamate release onto BLA principal neurons. To further confirm this finding, we found that boosting AEA levels restored paired pulse ratio of eEPSCs in kindled rats (Fig. 5D). Indeed, we found no differences in eEPSCs responses to paired stimuli when tested in BLA pyramidal neurons from kindled rats given URB597 with respect to those recorded from sham vehicle group, while the paired pulse ratio was statistically different between the kindled group treated with vehicle and the kindled group treated with URB597 (Fig. 5E). Since the CB1 receptor is also highly expressed on GABAergic terminals within the BLA (Yoshida et al., 2011), we examined the effect of URB597 on BLA GABA transmission (Fig. 5F). We found no differences either in the sIPSCs frequency or in the sIPSCs amplitude recorded in pyramidal neurons of the sham group treated with either URB597 or vehicle (Fig. 5G, H). Moreover, URB597 did not affect kindling-induced reduction of sIPSC frequency, since we found no difference between sIPSCs of cells recorded from kindled group treated with URB597 or vehicle (Fig. 5G). The paired pulse ratio of eIPSCs (Fig. 5I) was also not different in

\footnotetext{
current steps was similar in pyramidal neurons from sham $(n=10,9)$ and kindled rats $(n=10,10)$. Two-way RM ANOVA with current $F_{(13,234)}=49.35, p<0.0001$ and seizures $F_{(1,18)}=0.17, p=0.69$ as factors; interaction: $F_{(13,234)}$ $=0.94, p=0.51$. Representative traces and histograms $(\boldsymbol{H}$, I) show that relative to sham rats, kindled rats display increased sEPSC frequency ( $\boldsymbol{H}$, sham $n=12,7$, kindled $n=12,6$; unpaired $t$ test: $\left.t_{(22)}=5.35, p<0.0001\right)$ without significant effect on $\mathrm{SEPSC}$ amplitude $(\boldsymbol{H}$, sham $n=12,7$, kindled $n=12$, 6; unpaired $t$ test: $t_{(22)}=0.78, p=0.44$ ) and decreased paired pulse ratio of EPSC (I, sham $n=10,6$, kindled $n=10,5$, unpaired $t$ test: $\left.t_{(18)}=2.38, p=0.029\right)$. Representative traces and histograms $(\boldsymbol{J}, \boldsymbol{K})$ show that relative to sham rats, kindled rats display decreased sIPSC frequency $(J$, sham $n=12,5$, kindled $n=12,6$; unpaired $t$ test: $\left.t_{(22)}=3.91, p=0.0008\right)$ without significant effect on sIPSC amplitude ( $J$, sham $n=12,5$, kindled $n=12,6$; unpaired $t$ test: $\left.t_{(22)}=0.58, p=0.57\right)$, and increased paired pulse ratio of IPSC ( $K$, sham $n=16,9$, kindled $n=12,7$; unpaired $t$ test: $\left.t_{(26)}=2.32, p=0.028\right)$. Data are expressed as mean \pm SEM; ${ }^{*} p<0.05$ and ${ }^{* *} p<0.001$.
} 

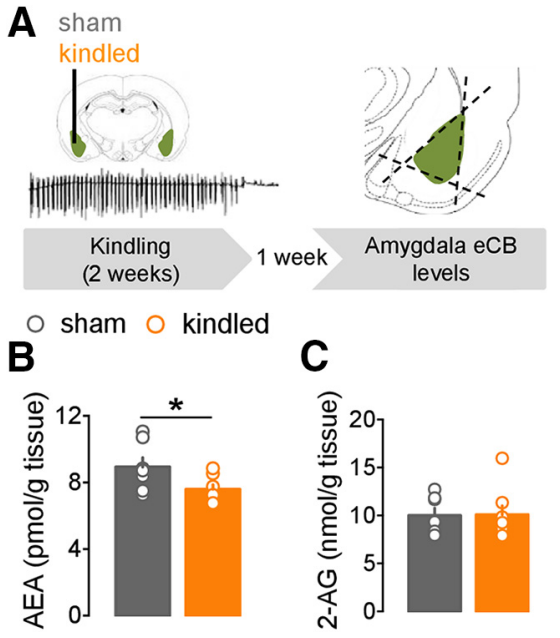

Figure 3. Repeated amygdala seizures reduce AEA content in the amygdala leaving 2-AG levels unaltered. Experimental design for the determination of the effect of repeated amygdala seizures on AEA and 2-AG levels in the amygdala $(\boldsymbol{A})$. Kindled rats $(n=8)$ presented decreased AEA levels (pmol/g tissue) in the amygdala compared with sham rats $(n=7 ; \boldsymbol{B}$, unpaired $t$ test: $\left.t_{(13)}=2.27, p=0.041\right)$. There were no differences in amygdala 2-AG levels (nmol/g tissue) between the two experimental groups ( $\boldsymbol{C}$, unpaired $t$ test: $t_{(13)}=0.068, p=$ 0.95). Data are expressed as mean $\pm \mathrm{SEM} ;{ }^{*} p<0.05$.

the kindled group treated with either URB597 or vehicle (Fig. 5J). These data demonstrate that AEA augmentation dampened seizure-induced increased presynaptic glutamate release but had no significant effect on seizure-induced impairment of presynaptic GABA release. We then investigated whether the modulatory effect of URB597 on glutamatergic but not GABAergic terminals was sufficient to restore I-E balance altered by repeated amygdala seizures. As expected, pyramidal neurons of the kindled group displayed a significantly reduced I-E ratio when compared with the sham group which was restored following AEA augmentation in kindled rats (Fig. $5 K, L$ ).

\section{Repeated amygdala seizures alter both tonic and phasic eCB signaling}

Tonic eCB signaling has been reported in various brain regions (Oliet et al., 2007; Lee et al., 2015) as well as in the BLA (Zhu and Lovinger, 2005). Since we found a persistent alteration of AEA content in the amygdala, we tested whether eCB signaling tonically modulates presynaptic neurotransmitter release in the BLA and whether AEA downregulation has an impact on the tonic $\mathrm{eCB}$ activity. Tonic eCB signaling can be observed as an increase in basal synaptic activity following pharmacological blockade of CB1 receptors. Here, we recorded either eEPSCs or eIPSCs before and after bath application of the CB1 receptor antagonist AM251 $(2 \mu \mathrm{M})$ in sham and kindled rats. We found that AM251 caused a significant increase of eEPSC amplitude (Fig. 6A-C) without affecting eIPSC amplitude (Fig. 6D-F) of pyramidal neurons recorded from the sham group, indicating that eCBs signaling tonically controls basal glutamate transmission, but not GABA transmission, in the BLA. Interestingly, bath application of AM251 did not produce any significant increase in eEPSC amplitude in the kindled group (Fig. $6 B$ ), indicating that tonic eCB control of glutamate release in the BLA is altered by repeated amygdala seizures.

Activity-dependent phasic mode of eCB mobilization represents the principal mechanism by which eCBs mediate short- and long-term forms of plasticity at both excitatory and inhibitory synapses. While depolarization-induced short-term suppression of neurotransmitter release is exclusively performed by 2-AG action at presynaptic CB1 receptors in many brain regions (Kano et al., 2009), including the BLA (Yoshida et al., 2011), iLTD in the BLA is likely mediated by AEA (Marsicano et al., 2002; Azad et al., 2004). Consistent with previous reports (Marsicano et al., 2002), we found that low-frequency stimulation (iLFS; 100 pulses at $1 \mathrm{~Hz}$ ) to the external capsule was sufficient to induce LTD of eIPSCs (iLTD) recorded in the BLA pyramidal neurons from sham vehicle rats (Fig. $6 G-I$ ). In contrast, iLFS did not trigger any significant iLTD in the kindled group when injected with vehicle, while pretreatment with URB597 was able to rescue iLTD induction in kindled rats (Fig. 6G-I). Together, these findings provide evidence that, within the BLA, both tonic and phasic eCB signaling are impaired following recurrent seizure activity.

\section{Boosting AEA signaling restores eCB-mediated long-term synaptic plasticity in BLA following repeated amygdala seizures}

Synaptic plasticity within the amygdala is crucial for fear memory consolidation (Nabavi et al., 2014) and the LA is thought to be the storage site of CS-US associations with the basal nuclei (BA) that constitute an essential relay of potentiated LA activity. LA-BA pathway has been shown to be an important site of plasticity (Rammes et al., 2000; Azad et al., 2004), particularly in modulating fear memory consolidation (Anglada-Figueroa and Quirk, 2005; Amano et al., 2011). Moreover, it has been shown that $\mathrm{eCB}$ signaling influences plasticity in this pathway (Marsicano et al., 2002; Azad et al., 2004). Here, we tested whether repeated amygdala seizures affected the capability of BLA synapses to undergo long-term potentiation (LTP) of the LA-BA pathway. We observed that HFS (four trains of 100 pulses at $100 \mathrm{~Hz}$ ) to the LA caused a small but reliable LTP of field EPSP (fEPSP) amplitude in BA (Fig. 7A-C). However, LTP could be induced in kindled rats as well suggesting that repeated seizure activity does not alter LTP induction and maintenance (Fig. $7 A-C$ ). It has been reported that LTP can be modulated by eCBmediated iLTD in many brain regions (Chevaleyre et al., 2006) including the BLA (Azad et al., 2004). Since we did find that repeated seizure activity in the amygdala impairs iLTD (Fig. 6GI), we attempted to induce LTP in the BLA when it was preceded by iLFS-inducing iLTD (100 pulses at $1 \mathrm{~Hz}$ ). Azad and colleagues have shown that in the BLA the magnitude of LTP is significantly enhanced if the HFS is preceded by iLFS (Azad et al., 2004). Accordingly, we observed that when iLFS was induced $10 \mathrm{~min}$ before HFS, the resulting LTP was significantly enhanced in sham/vehicle rats (Fig. 7D-F). However, iLTD-induced enhancement of LTP was completely absent in the kindled group treated with vehicle (Fig. 7G-I). Since the iLTD could be restored by pretreatment of URB597 as shown above (Fig. 6G-I), we tested whether AEA augmentation could restore the proper iLTDmediated enhancement of LTP. Indeed, we found that iLTDmediated enhanced LTP could be induced in the kindled group treated with URB597 (Fig. 7J-L), indicating that repeated seizure activity in the amygdala affects phasic AEA signaling to GABA transmission within the BLA, which consequently alters the magnitude of LTP at LA-BA synapses.

\section{Discussion}

Here, we showed for the first time that repeated seizure activity in the amygdala caused a persistent and maintained increase in 

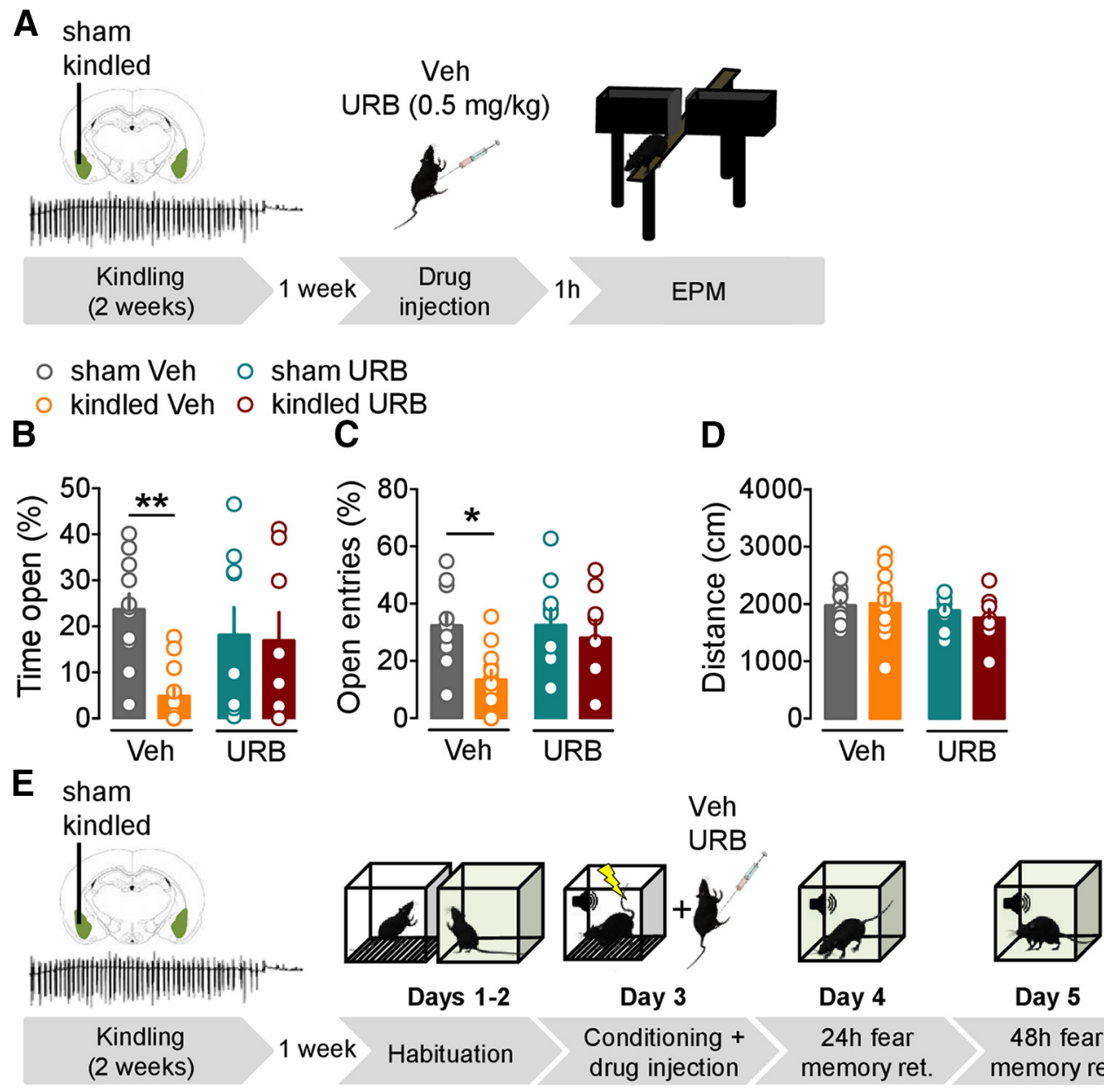

Days 1-2

Day 3

Day 4

Day 5

$\begin{array}{llcc}\text { week Habituation } & \begin{array}{l}\text { Conditioning }+ \\ \text { drug injection }\end{array} & \begin{array}{c}24 \mathrm{~h} \text { fear } \\ \text { memory ret. }\end{array} & \begin{array}{c}48 \mathrm{~h} \text { fear } \\ \text { memory ret. }\end{array}\end{array}$
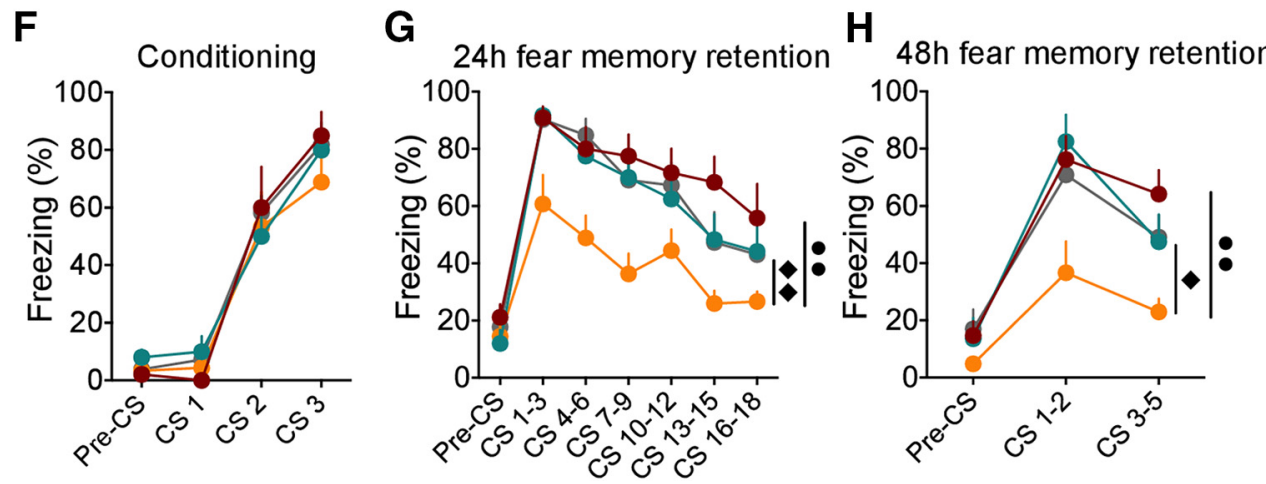

Figure 4. The FAAH inhibitor URB597 reverts the detrimental effects of repeated amygdala seizures on anxiety-like behavior and 24- and 48-h fear memory retention. Schematic representation of the experimental design for the assessment of URB597 effect on repeated amygdala seizure-induced anxiety-like behavior $(\boldsymbol{A})$. URB597 treatment reverted repeated amygdala seizureinduced increase of anxiety-like behavior on the EPM $(\boldsymbol{B}-\boldsymbol{D})$. Effects of amygdala kindling in rats treated with either vehicle or URB597 on percentage time spent in the open arms ( $\boldsymbol{B}$, two-way ANOVA, seizures effect: $F_{(1,36)}=5.49, p=0.025$; drug effect: $F_{(1,36)}=0.59, p=0.45$; interaction: $\left.F_{(1,36)}=4.23, p=0.047\right)$, open arm entries $\left(C\right.$, two-way ANOVA, seizures effect: $F_{(1,36)}=6.18$, $p=0.018$; drug effect: $F_{(1,36)}=2.40, p=0.13$; interaction: $\left.F_{(1,36)}=2.36, p=0.13\right)$, and total distance traveled ( $\boldsymbol{D}$, two-way ANOVA, seizures effect: $F_{(1,36)}=0.11, p=0.74$; drug effect: $F_{(1,36)}$ $=1.64, p=0.21$; interaction: $\left.F_{(1,36)}=0.38, p=0.54\right)$. Schematic representation of the experimental design for the assessment of URB597 effect on repeated amygdala seizure-induced alterations of fear memory dynamics $(\boldsymbol{E})$. URB597 treatment rescued repeated amygdala seizure-induced impairment of fear expression 24 and $48 \mathrm{~h}$ after conditioning $(\boldsymbol{F}-\boldsymbol{H})$. Percentage freezing during cued fear conditioning ( $\boldsymbol{F}$, two-way RM ANOVA, drug effect: $F_{(3,32)}=0.45, p=0.72$; CS-US effect: $F_{(3,96)}=119.2, p<0.0001$; interaction: $\left.F_{(9,96)}=0.49, p=0.88\right)$, 24-h fear memory retention (G, two-way RM ANOVA, drug effect: $F_{(3,32)}=6.33, p=0.0017$; $C$ effect: $F_{(6,192)}=51.16, p<0.0001$; interaction: $\left.F_{(18,192)}=1.19, p=0.27\right)$, and 48-h fear memory retention $(\boldsymbol{H}$, two-way RM ANOVA, drug effect: $F_{(3,32)}=5.06, p=0.0056$; CS effect: $F_{(2,64)}=75.34, p<0.0001$; interaction: $\left.F_{(6,64)}=2.15, p=0.06\right)$. Data are expressed as mean \pm SEM. Tukey's multiple comparison test: ${ }^{*} p<0.05$, ${ }^{* *} p<0.01$; Tukey's multiple comparison test for drug effect: $\diamond p<0.05, \diamond p<0.01$ kindled vehicle versus sham vehicle; $\bullet \bullet p<0.01$ kindled vehicle versus kindled URB597; $n=8-12$ per group.

anxiety-like behavior and reduced fear memory retention, which was associated with a sustained downregulation of AEA in the amygdala. This reduction of AEA signaling resulted in a loss of tonic inhibition over glutamatergic synapses and a loss of phasic control over GABAergic synapses, thus driving emotional alterations. Moreover, inhibition of FAAH normalized both behavioral and electrophysiological dysfunction in rats that had repeated seizures. 
A

sham Veh

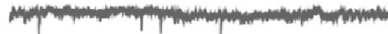

kindled Veh

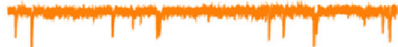

sham URB

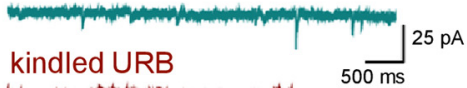

ming

D

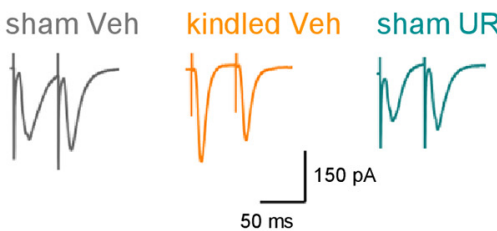

F

sham Veh

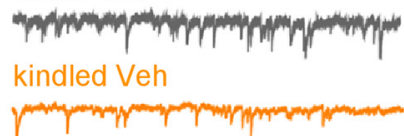

sham URB

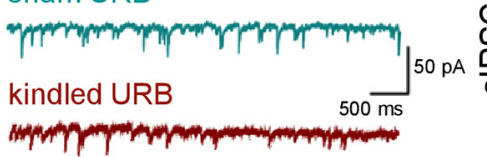

G
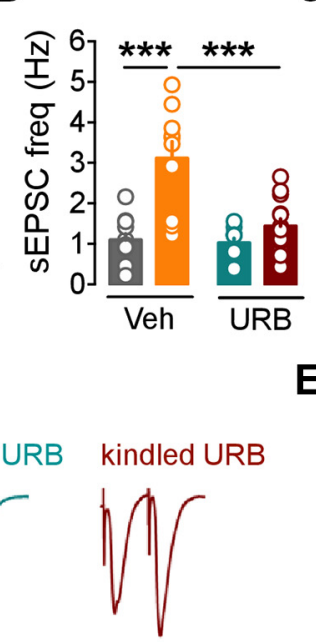

C

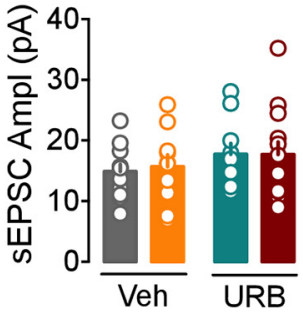

$E_{\widehat{x}}$

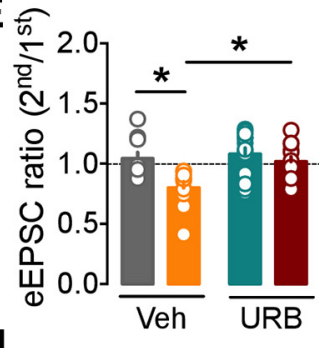

H
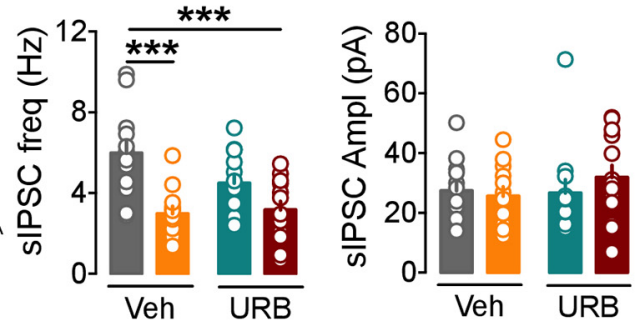

I
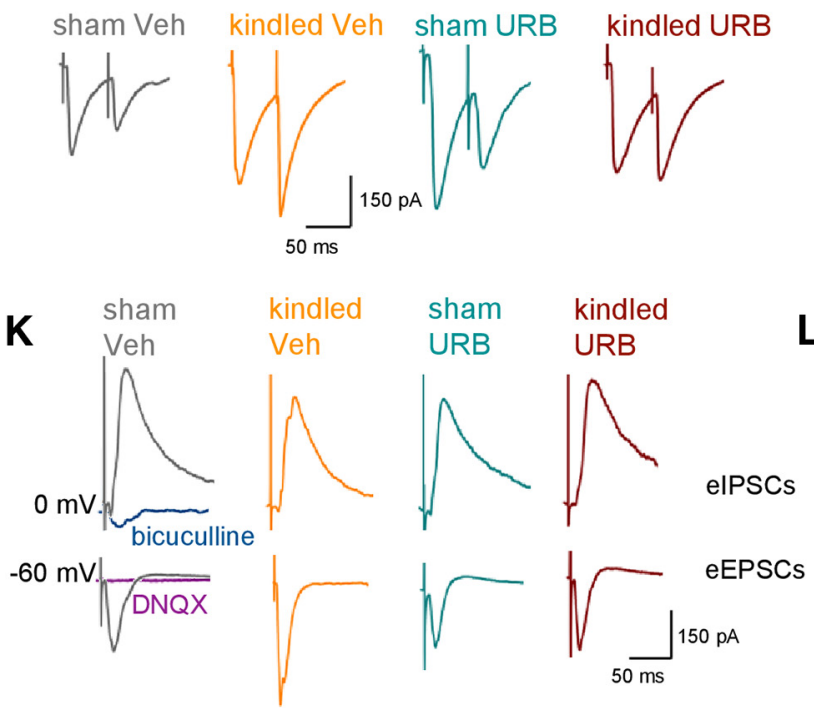

Figure 5. The FAAH inhibitor URB597 restores seizure-induced alteration of glutamatergic, but not GABAergic transmission, and re-establishes the I-E ratio in the BLA. Representative traces $(\boldsymbol{A})$ and histograms $(\boldsymbol{B}, \boldsymbol{C})$ show the effect of URB597 on sEPSCS in sham and kindled rats. URB597 treatment restored repeated amygdala seizure-induced increase of sEPSC frequency ( $\boldsymbol{B}$, sham vehicle, $n=12$, 9, kindled vehicle, $n=10$, 9, sham URB597, $n=10,7$, kindled URB597, $n=13$, 8; two-way ANOVA, drug effect: $F_{(1,41)}=14.18, p=0.0005$; seizures effect: $F_{(1,41)}=27.39, p<0.0001$; interaction: $\left.F_{(1,41)}=11.96, p=0.0013\right)$ without significant effect on sEPSC amplitude ( $C$, sham vehicle, $n=12$, 9, kindled vehicle, $n=10$, 9, sham URB597, $n=10,7$, kindled URB597, $n=13,8$; two-way ANOVA, drug effect: $F_{(1,41)}=1.83, p=0.18$; seizures effect: $F_{(1,41)}=0.048, p=0.83$; interaction: $F_{(1,41)}=$ $0.057, p=0.81)$. Moreover, URB597 treatment restored repeated amygdala seizure-induced reduction of paired pulse ratio of EPSC ( $\boldsymbol{D}, \boldsymbol{E}$, sham vehicle, $n=10,8$, kindled vehicle, $n=10,6$, sham URB597, $n=13,8$, kindled URB597, $n=13,7$; two-way ANOVA, drug effect: $F_{(1,42)}=5.81, p=0.020$; seizures effect: $F_{(1,42)}=8.40, p=0.0059$; interaction: $F_{(1.42)}=2.79, p=0.10$ ). Representative traces $(\boldsymbol{F})$ and histograms $(\boldsymbol{G}, \boldsymbol{H})$ show the effect of URB597 treatment on sIPSCS in sham and kindled rats. URB597 treatment did not affect repeated amygdala seizure-induced decrease of sIPSC frequency ( $G$, sham vehicle, $n=12,9$,
Basal levels of AEA tightly orchestrate presynaptic activity onto BLA neurons and, consequently, emotional behavior (Morena et al., 2019). While AEA levels, together with 2-AG, transiently rise during an acute seizure in the brain region involved in seizure activity (Marsicano et al., 2003; Wallace et al., 2003), the chronic effect of repeated seizure activity on $\mathrm{eCB}$ content has received limited attention in animal models of epilepsy. Chen and colleagues (Chen et al., 2003) found that in the febrile seizure model, there are no changes in hippocampal eCB levels one week after seizures. Conversely, we found that AEA but not 2-AG levels are persistently downregulated in the amygdala one week after the last seizure. Consistent with our finding, similar results have been reported in a clinical study where AEA content was significantly lower in the cerebrospinal fluid of persons with TLE (Romigi et al., 2010). Our data provide evidence that, while AEA signaling is engaged after a seizure to dampen excessive neuronal activity and re-establish the homeostatic preseizure condition (Marsicano et al., 2003), repeated

kindled vehicle, $n=12,9$, sham URB597, $n=12,8$, kindled URB597, $n=13$, 8; two-way ANOVA, drug effect: $F_{(1,45)}=1.81, p=0.19$; seizures effect: $F_{(1,45)}=$ 20.09, $p<0.0001$; interaction: $F_{(1,45)}=3.03$, $p=0.089)$ and had no effect on sIPSC amplitude $(\boldsymbol{H}$, sham vehicle, $n=12,9$, kindled vehicle, $n=12,9$, sham URB597, $n=12,8$, kindled URB597, $n=13,8$; two-way ANOVA, drug effect: $F_{(1,45)}=0.55, p=0.46$; seizures effect: $F_{(1,45)}=0.20, p=0.65$; interaction: $\left.F_{(1,45)}=0.87, p=0.36\right)$. URB597 treatment did not affect repeated amygdala seizure-induced increase of paired pulse ratio of IPSC $(\boldsymbol{I}, \boldsymbol{J}$, sham vehicle, $n=21,13$, kindled vehicle, $n=11,7$, sham URB597, $n=17,9$, kindled URB597, $n=23,15$; two-way ANOVA, drug effect: $F_{(1,68)}=1.73, p=0.19$; seizures effect: $F_{(1,68)}=$ $21.59, p<0.0001$; interaction: $\left.F_{(1,68)}=0.40, p=0.53\right)$. Representative traces $(\boldsymbol{K})$ show the effect of repeated amygdala seizures and FAAH inhibition on the I-V relationship for pure excitatory (blocked by $20 \mu \mathrm{m}$ DNQX, below), and pure inhibitory (blocked by $20 \mu \mathrm{m}$ bicuculline, above) evoked synaptic currents. Responses were recorded at holding potentials of -60 and $0 \mathrm{mV}$, respectively. URB597 restored repeated amygdala seizure-induced reduction of I-E ratio in kindled rats ( $\boldsymbol{L}$, sham vehicle, $n=11,6$, kindled vehicle, $n=11,6$, sham URB597, $n=9$, 5, kindled URB597, $n=7,5$; twoway ANOVA, drug effect: $F_{(1,33)}=0.92, p=0.35$; seizures effect: $F_{(1,33)}=1.34, p=0.26$; interaction: $F_{(1,33)}=$ $10.70, p=0.0025)$. Data are expressed as mean \pm SEM. Tukey's multiple comparison test: ${ }^{*} p<0.05$, ${ }^{* *} p<0.01,{ }^{* * *} p<0.001$. 


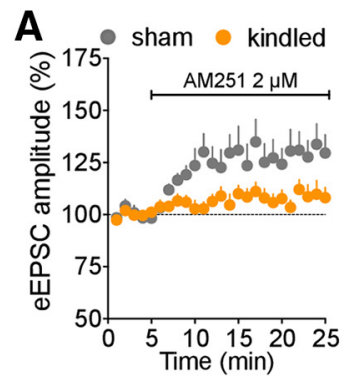

\section{D}

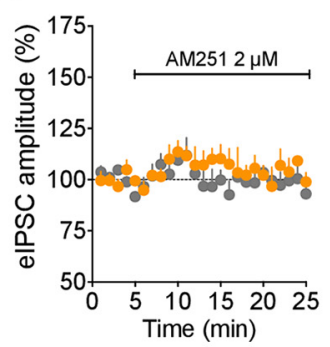

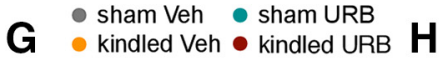

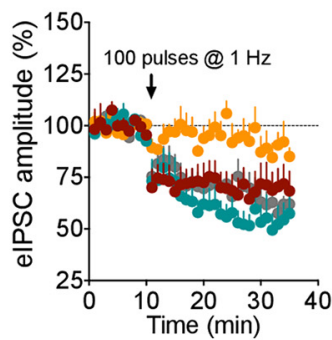

B

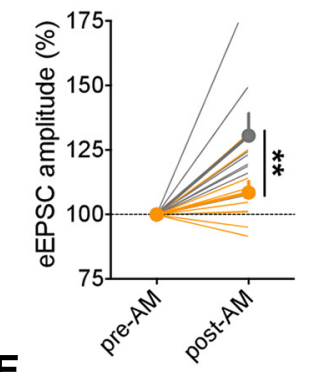

E

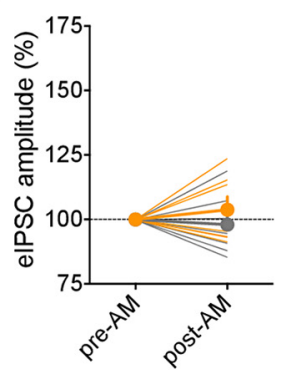

C

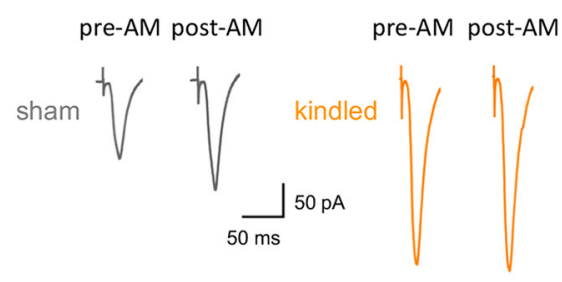

F

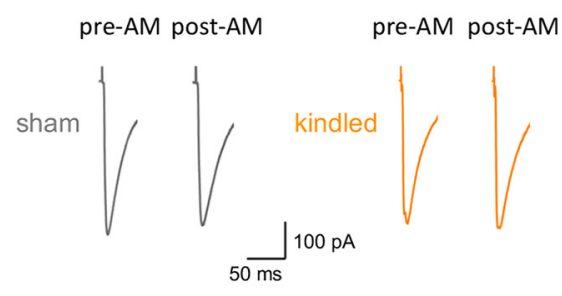

I

pre-LFS post-LFS

pre-LFS post-LFS
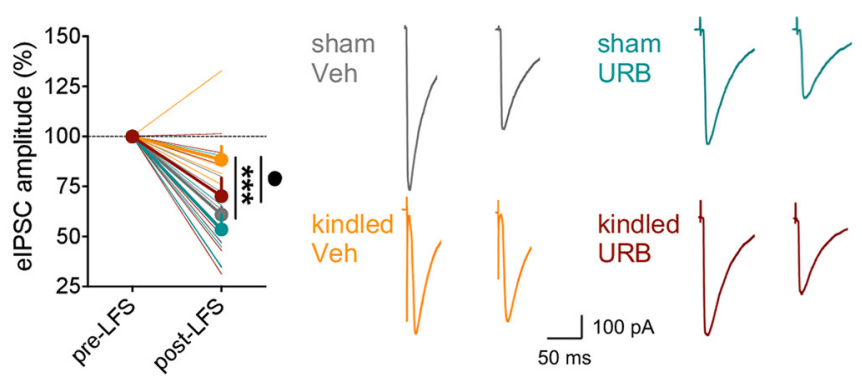

Figure 6. Repeated amygdala seizures alter both tonic and phasic eCB signaling. Graphs $(\boldsymbol{A}, \boldsymbol{B})$ and sample traces $(\boldsymbol{C})$ of eEPSC showing that bath application of the $C B 1$ receptor antagonist AM251 increased the amplitude of eEPSC in sham but not kindled rats ( $\boldsymbol{B}$, sham, $n=8,6$, kindled, $n=9$, 7; two-way RM ANOVA, seizures effect: $F_{(1,15)}=5.48, p=0.034 ;$ AM251 effect: $F_{(1,15)}$ $=17.04, p=0.0009$; interaction: $\left.F_{(1,15)}=5.48, p=0.034\right)$. Graphs $(\boldsymbol{D}, \boldsymbol{E})$ and sample traces $(\boldsymbol{F})$ of elPSC showing that bath application of the CB1 receptor antagonist AM251 did not affect the amplitude of elPSC in either sham or kindled rats $\left(\boldsymbol{E}\right.$, sham, $n=7,7$, kindled, $n=7,7$; two-way RM ANOVA, seizures effect: $F_{(1,12)}=0.73, p=0.41 ;$ AM251 effect: $F_{(1,12)}=0.063, p=0.81$; interaction: $\left.F_{(1,12)}=0.73, p=0.41\right)$. Graphs $(\boldsymbol{G}, \boldsymbol{H})$ and sample traces $(\boldsymbol{I})$ of elPSC showing that LTD induction was blocked in kindled vehicle rats $(n=8,8)$, compared with sham vehicle rats $(n=9,9)$ and was restored in kindled rats treated with URB597 ( $H$, sham URB597, $n=7,6$, kindled URB597, $n=8,8$; two-way RM ANOVA, drug effect: $F_{(3,28)}=4.66, p=0.009 ;$ LFS effect: $F_{(1,28)}=85.45, p<0.0001$; interaction: $\left.F_{(3,28)}=4.66, p=0.009\right)$. Data in $\boldsymbol{B}, \boldsymbol{E}$ show the mean of first 5-min recording before AM251 bath application (pre-AM) and from 21- to 25-min recording (post-AM). Data in $\boldsymbol{H}$ show the mean of the first 10-min recording before LFS (pre-LFS) and from 31- to 35-min recording (post-LFS). Data are expressed as mean \pm SEM. Tukey's multiple comparison test: ${ }^{* *} p<0.01,{ }^{* *} p<0.001$ sham (vehicle) versus kindled (vehicle), $\bullet p<0.05$ kindled vehicle versus kindled URB597.

seizure activity causes a persistent allostatic downregulation of AEA signaling in the amygdala, which might drive presynaptic alterations of BLA pyramidal neurons and subsequently interictal emotional dysfunction. Indeed, in line with previous findings, we found that repeated seizure-induced alterations of BLA principal neurons is confined to the synaptic level while intrinsic neuronal properties are unaffected by repeated seizure activity (Shoji et al., 1998; Schubert et al., 2005). In addition to that, here, we showed that persistent synaptic changes induced by repeated seizures are restricted to presynaptic glutamatergic and GABAergic terminals causing unbalanced I-E transmission onto BLA pyramidal neurons. Importantly, it has been reported that presynaptic alterations of amygdala glutamate transmission with consequent abnormal hyperactivity of the BLA are associated with anxietylike phenotypes (Aroniadou-Anderjaska et al., 2012; LoweryGionta et al., 2018), and low AEA content in the amygdala is associated with increased BLA activity, which drives anxiety-like behavior (Gray et al., 2015). The fact that our data showed that systemic administration of the FAAH inhibitor URB597 dampened both glutamatergic presynaptic hyperactivity and anxiety- like behavior in kindled rats strongly indicates that deficient AEA signaling within the BLA promotes BLA hyperexcitability and the development of interictal anxiety. This finding presents a new potential mechanism driving comorbid anxiety in seizure related disorders.

eCB signaling exerts presynaptic tonic control of both glutamate and GABA release shaping the synaptic strength of neuronal networks (Zhu and Lovinger, 2005; Oliet et al., 2007). Thereby, the downregulation of AEA content in the BLA following kindling likely restricts the tonic $\mathrm{eCB}$ action on glutamatergic neurotransmitter release causing BLA hyperactivity. Although it has been reported that tonic eCB signaling occurs at GABAergic synapses in the hippocampus (Lee et al., 2015), tonic action of $\mathrm{eCB}$ on excitatory transmission in the BLA has also been demonstrated (Yasmin et al., 2020). In line with this latter study, we observed that, in sham rats, CB1 receptor blockade revealed a tonic $\mathrm{eCB}$ action on glutamate but not on GABA neurotransmission within the BLA. Moreover, we found that this tonic control by eCBs on excitatory transmission is impaired in kindled rats. These data together with the findings that the FAAH inhibitor 
A sham Veh $\bullet$ kindled Veh B

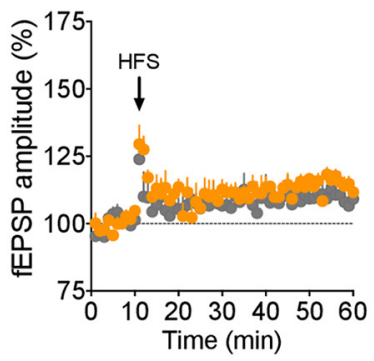

D sham Veh

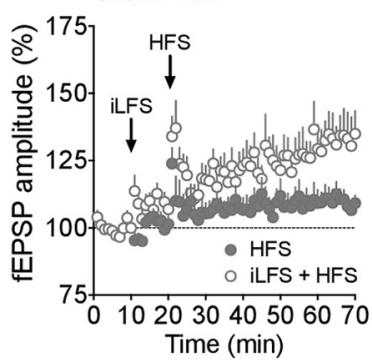

G kindled Veh

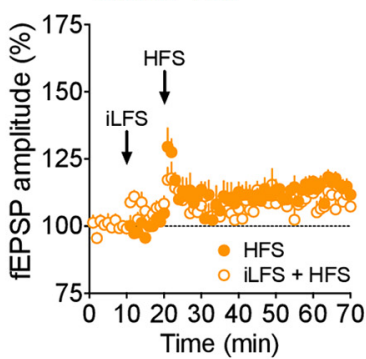

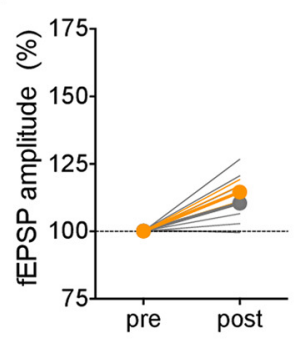

E

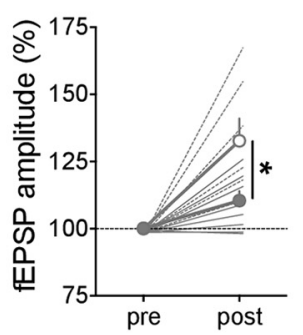

H

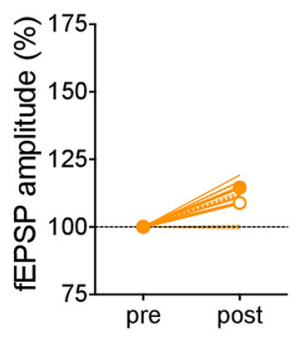

C

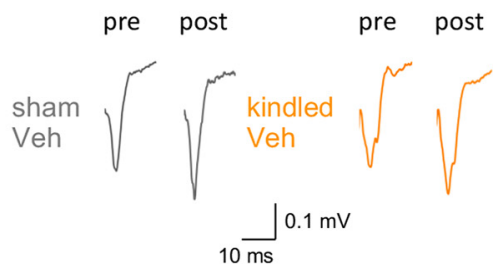

$\mathbf{F}$

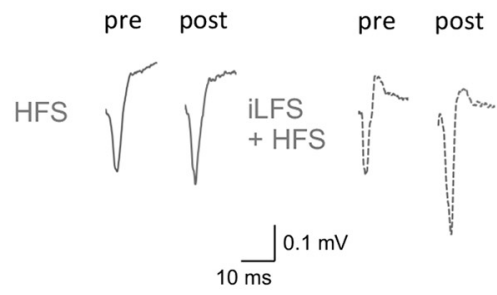

I

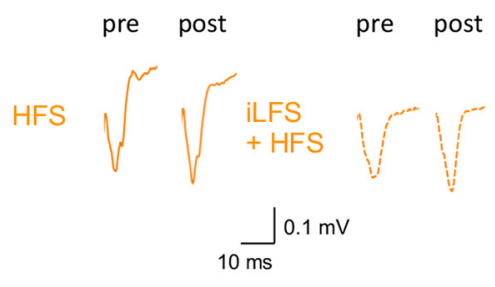

$\begin{array}{llll} & \text { sham Veh } & \circ & \text { sham URB } \\ & \text { kindled Veh } & \circ & \text { kindled URB }\end{array}$

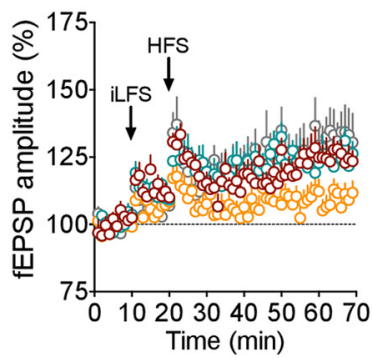

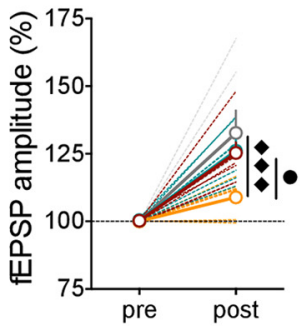

L

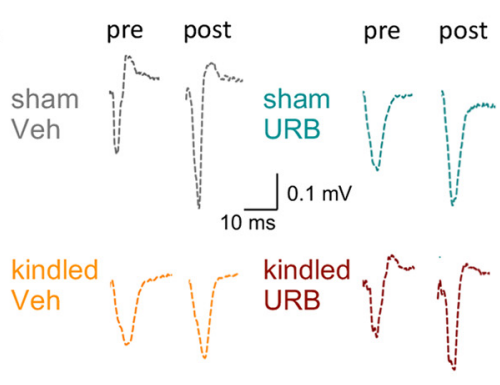

Figure 7. FAAH inhibitor restores long-term synaptic plasticity in BLA following repeated amygdala seizures. Graphs $(A, B)$ and sample traces $(\boldsymbol{C})$ of fEPSPs recorded in the BLA showing that HFS induces LTP in both sham vehicle $\left(n=8\right.$ slices, 7 rats), and kindled vehicle $(n=5,5)$ rats $\left(\boldsymbol{B}\right.$; two-way RM ANOVA, seizures effect $F_{(1,11)}=0.75, p=0.40$; HFS effect $F_{(1,11)}=26.88$, $p=0.0003$; interaction $F_{(1,11)}=0.78, p=0.40$; Tukey's multiple comparison test: sham vehicle pre-HFS vs post-HFS, $p<0.05$; kindled vehicle pre-HFS vs post-HFS, $\left.p<0.01\right)$. Graphs $(\boldsymbol{D}, \boldsymbol{E}, \boldsymbol{G}$, $\boldsymbol{H})$ and sample traces $(\boldsymbol{F}, \boldsymbol{I})$ show that, when iLFS is applied 10 min before HFS, the resulting LTP is significantly enhanced in sham vehicle $\left(\boldsymbol{E}, n=7,5\right.$; two-way RM ANOVA, iLFS effect: $F_{(1,13)}$ $=6.63, p=0.023$; HFS effect: $F_{(1,13)}=24.64, p=0.0003$; interaction: $\left.F_{(1,13)}=6.70, p=0.023\right)$ but not in kindled rats $\left(\boldsymbol{H}, n=6,6\right.$; two-way RM ANOVA, iLFS effect: $F_{(1,9)}=2.68, p=0.14$; HFS effect: $F_{(1,9)}=43.34, p=0.0001$; interaction: $\left.F_{(1,9)}=2.54, p=0.15\right)$. Graphs $(\boldsymbol{J}, \boldsymbol{K})$ and sample traces $(\boldsymbol{L})$ show that treatment with URB597 significantly enhanced LTP in kindled rats when iLFS was applied 10 min before HFS ( $K$, sham URB597, $n=7$, 4, kindled URB597 $n=8$, 5; two-way RM ANOVA, drug effect: $F_{(3,24)}=3.38, p=0.035$; iLFS +HFS effect: $F_{(1,24)}=76.08$, $p<0.0001$; interaction: $F_{(3,24)}=3.32, p=0.037$ ). Data in $\boldsymbol{B}, \boldsymbol{E}, \boldsymbol{H}, \boldsymbol{K}$ show the mean of first 10-min baseline recording before HFS or iLFS (pre) and the last 10-min recording after HFS (post). Sham vehicle and kindled vehicle data are repeated in the graphs as they belong to the same experimental design. Data are expressed as mean \pm SEM. Tukey's multiple comparison test: ${ }^{*} p<0.05$; Tukey's multiple comparison test for drug effect: $\diamond \diamond p<0.001$ kindled vehicle versus sham vehicle; $\bullet p<0.05$ kindled vehicle versus kindled URB597.

dampens seizure-induced glutamate hyperactivity without affecting GABA transmission provide strong evidence that allostatic maladaptation of AEA signaling in the amygdala impairs eCB mediated tonic control over glutamate release, which in turn causes enhanced BLA excitation and eventually an anxiety-like phenotype. It is important to mention that, together with AEA, 2-AG subserves tonic eCB signaling (Lee et al., 2015). However, a recent study has demonstrated that, within the BLA, inhibition of 2-AG synthesis does not cause changes in basal glutamate and GABA transmission, ruling out a possible role of $2-A G$ in the eCB-mediated tonic control of neurotransmitter release onto BLA pyramidal neurons (Yasmin et al., 2020). On the other hand, constitutive $\mathrm{CB} 1$ receptor activity in the absence of an endogenous ligand, which tonically regulates neurotransmitter 
release, has also been reported and cannot be ruled out (Lee et al., 2015). Nevertheless, our data providing evidence for a crucial role of tonic AEA signaling loss following seizure-induced alterations in BLA physiology and emotional behavior which are paralleled by studies showing how stress exposure results in a decline in amygdala AEA signaling, causing enhanced BLA presynaptic glutamatergic transmission, which drives anxiety-like behavior (Gray et al., 2015; Yasmin et al., 2020).

Amygdala AEA signaling is also crucially involved in the consolidation of fear memory (Morena et al., 2014) and fear memory impairments are associated with alteration of AEA signaling (Morena et al., 2019). LTP and LTD in the amygdala are widely considered to be the synaptic basis underlying associative memory including emotional memory (Nabavi et al., 2014) and alterations of synaptic plasticity in the amygdala strongly affect fear memory dynamics (Marsicano et al., 2002; Nabavi et al., 2014). A central role of eCBs in modulating long-term synaptic plasticity has been widely demonstrated (Chevaleyre et al., 2006). In particular, within the hippocampus and amygdala, AEA signaling is involved in both LTP (Zimmermann et al., 2019) and LTD (Azad et al., 2004). Seizure activity alters synaptic plasticity in the hippocampus (Colangeli et al., 2017), and in the amygdala (Schubert et al., 2005), and a recent study showed that AEA augmentation is capable of restoring both short-term and long-term synaptic plasticity in the dentate gyrus after kindling of the perforant pathway (Colangeli et al., 2017). Therefore, it is conceivable that interictal fear memory dysfunction might be caused by alterations of AEA-dependent long-term plasticity within the BLA. LTD of GABA transmission (iLTD) is a form of synaptic plasticity consisting of long-term reduction of transmitter release from GABAergic terminals (Chevaleyre et al., 2006). Within the BLA, iLTD is mediated by AEA signaling, and it plays an important role in tuning the magnitude of LTP induced by HFS (Azad et al., 2004). Here, we found that, despite kindled rats displaying impaired fear memory formation, LTP induction in the amygdala is still intact after repeated seizure activity. Conversely, we did find both iLTD induction and iLTD-mediated LTP modulation significantly impaired following repeated amygdala seizures, indicating that repeated seizure activity alters synaptic plasticity specifically at GABA synapses. Structural and functional plasticity of GABAergic synapses in the BA has been shown to occur during fear conditioning (Kasugai et al., 2019), thereby, it is possible to speculate that alterations of GABA plasticity induced by seizures likely account for the altered fear memory retention in kindled rats. However, previous studies indicate that a persistent reduction of basal GABAergic activity together with a sustained increase of the excitatory drive within the BLA is generally associated with increased fear expression (Ehrlich et al., 2009). A possible explanation for this discrepancy is that synaptic plasticity occurring during associative learning requires a time-specific break in the balance of excitation and inhibition (Letzkus et al., 2015), thereby the persistent and unspecific disinhibition caused by repeated seizures likely affects the temporal specificity of local inhibitory network and the precise activation of glutamatergic activity to drive behavioral responses. In support of this interpretation, we found that FAAH inhibition normalized I-E balance within the BLA and restored activity-dependent eCB-induced depression of local inhibitory network in kindled rats. Thus, this suggests that the physiological role of AEA signaling within the BLA is to maintains homeostatic tonic control over glutamatergic transmission while exerting precise phasic control over GABA signaling which enables the induction of plasticity. Therefore, our data provide evidence that seizures persistently alter tonic AEA signaling at glutamatergic terminals to cause BLA hyperexcitability, which may contribute to elevations in anxiety-like behavior. Moreover, repeated amygdala seizures impair activity-dependent AEA signaling at GABAergic transmission within the BLA, which may account for the impairment in fear memory retention. In support of this hypothesis, enhancing AEA signaling through the inhibition of FAAH restored interictal alterations on emotional behavior. While the available body of literature supports the hypothesis that these effects are likely mediated, at least in part, via elevations in AEA/CB1 receptor signaling in the BLA proper, it is important to note that, in this study, the FAAH inhibitor was given systemically, thereby effects of AEA augmentation in other brain regions important for fear memory and anxiety cannot be ruled out. Indeed, it has been shown that modulating AEA signaling in the hippocampus or prefrontal cortex can influence fear memory consolidation and anxiety-like behavior (Rubino et al., 2008; Campos et al., 2010; Morena et al., 2014; Lisboa et al., 2015; Hartmann et al., 2019; Zimmermann et al., 2019).

In conclusion, our data show that allostatic maladaptation of AEA signaling plays a crucial role for the development of interictal emotional dysfunction, pinpointing AEA signaling and the FAAH enzyme as a chief target for the deployment of new therapeutic options for comorbid emotional alterations occurring in persons with epilepsy. Indeed, clinical studies have reported that genetic polymorphisms that decrease FAAH activity and increase basal AEA levels are associated with reduced anxiety, facilitated consolidation of emotional memories, and protection against negative emotional consequences following stress exposure (Spagnolo et al., 2016; Mayo et al., 2020b), and similar results have been reported in people treated with FAAH inhibitors (Mayo et al., 2020a). It is important to note that FAAH inhibitors suitable for human use that are safe, well tolerated, and lack abuse liability have been already developed ( $\mathrm{Li}$ et al., 2012; Mayo et al., 2020a) and could potentially be used in clinical trials to treat interictal emotional comorbidities. Moreover, given the potential anti-seizure effect of FAAH inhibitors (Colangeli et al., 2017), these data now indicate that FAAH inhibitors could have a potential two pronged therapeutic approach in seizure related disorders, being able to both reduce the severity of seizures themselves as well as alleviate the development of comorbid emotional alterations. This dual treatment approach offers an entirely new avenue into the therapeutics of seizure related disorders.

\section{References}

Acharjee S, Verbeek M, Gomez CD, Bisht K, Lee B, Benoit L, Sharkey KA, Benediktsson A, Tremblay ME, Pittman QJ (2018) Reduced microglial activity and enhanced glutamate transmission in the basolateral amygdala in early CNS autoimmunity. J Neurosci 38:9019-9033.

Adamec R, Blundell J, Burton P (2004) Anxiolytic effects of kindling role of anatomical location of the kindling electrode in response to kindling of the right basolateral amygdala. Brain Res 1024:44-58.

Amano T, Duvarci S, Popa D, Paré D (2011) The fear circuit revisited: contributions of the basal amygdala nuclei to conditioned fear. J Neurosci 31:15481-15489.

Anglada-Figueroa D, Quirk GJ (2005) Lesions of the basal amygdala block expression of conditioned fear but not extinction. J Neurosci 25:96809685.

Aroniadou-Anderjaska V, Fritsch B, Qashu F, Braga MF (2008) Pathology and pathophysiology of the amygdala in epileptogenesis and epilepsy. Epilepsy Res 78:102-116.

Aroniadou-Anderjaska V, Pidoplichko VI, Figueiredo TH, Almeida-Suhett CP, Prager EM, Braga MF (2012) Presynaptic facilitation of glutamate release in the basolateral amygdala: a mechanism for the anxiogenic and seizurogenic function of GluK1 receptors. Neuroscience 221:157-169. 
Azad SC, Monory K, Marsicano G, Cravatt BF, Lutz B, Zieglgänsberger W, Rammes G (2004) Circuitry for associative plasticity in the amygdala involves endocannabinoid signaling. J Neurosci 24:9953-9961.

Bedse G, Colangeli R, Lavecchia AM, Romano A, Altieri F, Cifani C, Cassano $\mathrm{T}$, Gaetani S (2014) Role of the basolateral amygdala in mediating the effects of the fatty acid amide hydrolase inhibitor URB597 on HPA axis response to stress. Eur Neuropsychopharmacol 24:1511-1523.

Botterill JJ, Fournier NM, Guskjolen AJ, Lussier AL, Marks WN, Kalynchuk LE (2014) Amygdala kindling disrupts trace and delay fear conditioning with parallel changes in Fos protein expression throughout the limbic brain. Neuroscience 265:158-171.

Campos AC, Ferreira FR, Guimarães FS, Lemos JI (2010) Facilitation of endocannabinoid effects in the ventral hippocampus modulates anxietylike behaviors depending on previous stress experience. Neuroscience 167:238-246.

Chen K, Ratzliff A, Hilgenberg L, Gulyás A, Freund TF, Smith M, Dinh TP, Piomelli D, Mackie K, Soltesz I (2003) Long-term plasticity of endocannabinoid signaling induced by developmental febrile seizures. Neuron 39:599-611.

Chen SD, Wang YL, Liang SF, Shaw FZ (2016) Rapid amygdala kindling causes motor seizure and comorbidity of anxiety- and depression-like behaviors in rats. Front Behav Neurosci 10:129.

Chevaleyre V, Takahashi KA, Castillo PE (2006) Endocannabinoid-mediated synaptic plasticity in the CNS. Annu Rev Neurosci 29:37-76.

Colangeli R, Pierucci M, Benigno A, Campiani G, Butini S, Di Giovanni G (2017) The FAAH inhibitor URB597 suppresses hippocampal maximal dentate afterdischarges and restores seizure-induced impairment of short and long-term synaptic plasticity. Sci Rep 7:11152.

Colangeli R, Di Maio R, Pierucci M, Deidda G, Casarrubea M, Di Giovanni G (2019) Synergistic action of CB1 and 5-HT2B receptors in preventing pilocarpine-induced status epilepticus in rats. Neurobiol Dis 125:135145.

Di Maio R, Colangeli R, Di Giovanni G (2019) WIN 55,212-2 reverted pilocarpine-induced status epilepticus early changes of the interaction among $5-\mathrm{HT} 2 \mathrm{C} / \mathrm{NMDA} / \mathrm{CB} 1$ receptors in the rat hippocampus. ACS Chem Neurosci 10:3296-3306.

Eddy CM, Rickards HE, Cavanna AE (2011) The cognitive impact of antiepileptic drugs. Ther Adv Neurol Disord 4:385-407.

Ehrlich I, Humeau Y, Grenier F, Ciocchi S, Herry C, Lüthi A (2009) Amygdala inhibitory circuits and the control of fear memory. Neuron 62:757-771.

Farrell JS, Gaxiola-Valdez I, Wolff MD, David LS, Dika HI, Geeraert BL, Rachel Wang X, Singh S, Spanswick SC, Dunn JF, Antle MC, Federico P, Teskey GC (2016) Postictal behavioural impairments are due to a severe prolonged hypoperfusion/hypoxia event that is COX-2 dependent. Elife 5.

Farrell JS, Colangeli R, Wolff MD, Wall AK, Phillips TJ, George A, Federico P, Teskey GC (2017) Postictal hypoperfusion/hypoxia provides the foundation for a unified theory of seizure-induced brain abnormalities and behavioral dysfunction. Epilepsia 58:1493-1501.

Fournier NM, Botterill JJ, Marks WN, Guskjolen AJ, Kalynchuk LE (2013) Impaired recruitment of seizure-generated neurons into functional memory networks of the adult dentate gyrus following long-term amygdala kindling. Exp Neurol 244:96-104.

Gray JM, Vecchiarelli HA, Morena M, Lee TT, Hermanson DJ, Kim AB, McLaughlin RJ, Hassan KI, Kühne C, Wotjak CT, Deussing JM, Patel S, Hill MN (2015) Corticotropin-releasing hormone drives anandamide hydrolysis in the amygdala to promote anxiety. J Neurosci 35:3879-3892.

Haller J, Varga B, Ledent C, Barna I, Freund TF (2004) Context-dependent effects of CB1 cannabinoid gene disruption on anxiety-like and social behaviour in mice. Eur J Neurosci 19:1906-1912.

Hannesson DK, Pollock MS, Howland JG, Mohapel P, Wallace AE, Corcoran ME (2008) Amygdaloid kindling is anxiogenic but fails to alter object recognition or spatial working memory in rats. Epilepsy Behav 13:52-61.

Hartmann A, Fassini A, Scopinho A, Correa FM, Guimarães FS, Lisboa SF, Resstel LB (2019) Role of the endocannabinoid system in the dorsal hippocampus in the cardiovascular changes and delayed anxiety-like effect induced by acute restraint stress in rats. J Psychopharmacol 33:606-614.

Helfer V, Deransart C, Marescaux C, Depaulis A (1996) Amygdala kindling in the rat: anxiogenic-like consequences. Neuroscience 73:971-978.
Hill MN, Tasker JG (2012) Endocannabinoid signaling, glucocorticoid-mediated negative feedback, and regulation of the hypothalamic-pituitary-adrenal axis. Neuroscience 204:5-16.

Kanner AM (2016) Management of psychiatric and neurological comorbidities in epilepsy. Nat Rev Neurol 12:106-116.

Kanner AM, Barry JJ, Gilliam F, Hermann B, Meador KJ (2010) Anxiety disorders, subsyndromic depressive episodes, and major depressive episodes: do they differ on their impact on the quality of life of patients with epilepsy? Epilepsia 51:1152-1158.

Kano M, Ohno-Shosaku T, Hashimotodani Y, Uchigashima M, Watanabe M (2009) Endocannabinoid-mediated control of synaptic transmission. Physiol Rev 89:309-380.

Kasugai Y, Vogel E, Hörtnagl H, Schönherr S, Paradiso E, Hauschild M, Göbel G, Milenkovic I, Peterschmitt Y, Tasan R, Sperk G, Shigemoto R, Sieghart W, Singewald N, Lüthi A, Ferraguti F (2019) Structural and functional remodeling of amygdala GABAergic synapses in associative fear learning. Neuron 104:781-794.e4.

Kathuria S, Gaetani S, Fegley D, Valiño F, Duranti A, Tontini A, Mor M, Tarzia G, La Rana G, Calignano A, Giustino A, Tattoli M, Palmery M, Cuomo V, Piomelli D (2003) Modulation of anxiety through blockade of anandamide hydrolysis. Nat Med 9:76-81.

LeDoux JE (2000) Emotion circuits in the brain. Annu Rev Neurosci 23:155184.

Lee SH, Ledri M, Tóth B, Marchionni I, Henstridge CM, Dudok B, Kenesei K, Barna L, Szabó SI, Renkecz T, Oberoi M, Watanabe M, Limoli CL, Horvai G, Soltesz I, Katona I (2015) Multiple forms of endocannabinoid and endovanilloid signaling regulate the tonic control of GABA release. J Neurosci 35:10039-10057.

Letzkus JJ, Wolff SB, Lüthi A (2015) Disinhibition, a circuit mechanism for associative learning and memory. Neuron 88:264-276

Li GL, Winter H, Arends R, Jay GW, Le V, Young T, Huggins JP (2012) Assessment of the pharmacology and tolerability of PF-04457845, an irreversible inhibitor of fatty acid amide hydrolase-1, in healthy subjects. Br J Clin Pharmacol 73:706-716.

Lisboa SF, Borges AA, Nejo P, Fassini A, Guimarães FS, Resstel LB (2015) Cannabinoid CB1 receptors in the dorsal hippocampus and prelimbic medial prefrontal cortex modulate anxiety-like behavior in rats: additional evidence. Prog Neuropsychopharmacol Biol Psychiatry 59:76-83.

Lowery-Gionta EG, Crowley NA, Bukalo O, Silverstein S, Holmes A, Kash TL (2018) Chronic stress dysregulates amygdalar output to the prefrontal cortex. Neuropharmacology 139:68-75.

Ludányi A, Eross L, Czirják S, Vajda J, Halász P, Watanabe M, Palkovits M, Maglóczky Z, Freund TF, Katona I (2008) Downregulation of the CB1 cannabinoid receptor and related molecular elements of the endocannabinoid system in epileptic human hippocampus. J Neurosci 28:29762990.

Marsicano G, Wotjak CT, Azad SC, Bisogno T, Rammes G, Cascio MG, Hermann H, Tang J, Hofmann C, Zieglgänsberger W, Di Marzo V, Lutz B (2002) The endogenous cannabinoid system controls extinction of aversive memories. Nature 418:530-534.

Marsicano G, Goodenough S, Monory K, Hermann H, Eder M, Cannich A, Azad SC, Cascio MG, Gutiérrez SO, van der Stelt M, López-Rodriguez ML, Casanova E, Schütz G, Zieglgänsberger W, Di Marzo V, Behl C, Lutz B (2003) CB1 cannabinoid receptors and on-demand defense against excitotoxicity. Science 302:84-88.

Mayo LM, Asratian A, Lindé J, Morena M, Haataja R, Hammar V, Augier G, Hill MN, Heilig M (2020a) Elevated anandamide, enhanced recall of fear extinction, and attenuated stress responses following inhibition of fatty acid amide hydrolase: a randomized, controlled experimental medicine trial. Biol Psychiatry 87:538-547.

Mayo LM, Asratian A, Lindé J, Holm L, Nätt D, Augier G, Stensson N, Vecchiarelli HA, Balsevich G, Aukema RJ, Ghafouri B, Spagnolo PA, Lee FS, Hill MN, Heilig M (2020b) Protective effects of elevated anandamide on stress and fear-related behaviors: translational evidence from humans and mice. Mol Psychiatry 25:993-1005.

Morena M, Roozendaal B, Trezza V, Ratano P, Peloso A, Hauer D, Atsak P, Trabace L, Cuomo V, McGaugh JL, Schelling G, Campolongo P (2014) Endogenous cannabinoid release within prefrontal-limbic pathways affects memory consolidation of emotional training. Proc Natl Acad Sci USA 111:18333-18338.

Morena M, De Castro V, Gray JM, Palmery M, Trezza V, Roozendaal B, Hill MN, Campolongo P (2015) Training-associated emotional arousal shapes 
endocannabinoid modulation of spatial memory retrieval in rats. J Neurosci 35:13962-13974.

Morena M, Patel S, Bains JS, Hill MN (2016a) Neurobiological interactions between stress and the endocannabinoid system. Neuropsychopharmacology 41:80-102.

Morena M, Leitl KD, Vecchiarelli HA, Gray JM, Campolongo P, Hill MN (2016b) Emotional arousal state influences the ability of amygdalar endocannabinoid signaling to modulate anxiety. Neuropharmacology 111:5969.

Morena M, Aukema RJ, Leitl KD, Rashid AJ, Vecchiarelli HA, Josselyn SA, Hill MN (2019) Upregulation of anandamide hydrolysis in the basolateral complex of amygdala reduces fear memory expression and indices of stress and anxiety. J Neurosci 39:1275-1292.

Nabavi S, Fox R, Proulx CD, Lin JY, Tsien RY, Malinow R (2014) Engineering a memory with LTD and LTP. Nature 511:348-352.

Oliet SH, Baimoukhametova DV, Piet R, Bains JS (2007) Retrograde regulation of GABA transmission by the tonic release of oxytocin and endocannabinoids governs postsynaptic firing. J Neurosci 27:1325-1333.

Pinel JP, Rovner LI (1978) Experimental epileptogenesis: kindling-induced epilepsy in rats. Exp Neurol 58:190-202.

Qi M, Morena M, Vecchiarelli HA, Hill MN, Schriemer DC (2015) A robust capillary liquid chromatography/tandem mass spectrometry method for quantitation of neuromodulatory endocannabinoids. Rapid Commun Mass Spectrom 29:1889-1897.

Racine RJ (1972) Modification of seizure activity by electrical stimulation. II. Motor seizure. Electroencephalogr Clin Neurophysiol 32:281-294.

Rammes G, Steckler T, Kresse A, Schütz G, Zieglgänsberger W, Lutz B (2000) Synaptic plasticity in the basolateral amygdala in transgenic mice expressing dominant-negative cAMP response element-binding protein (CREB) in forebrain. Eur J Neurosci 12:2534-2546.

Romigi A, Bari M, Placidi F, Marciani MG, Malaponti M, Torelli F, Izzi F, Prosperetti C, Zannino S, Corte F, Chiaramonte C, Maccarrone M (2010) Cerebrospinal fluid levels of the endocannabinoid anandamide are reduced in patients with untreated newly diagnosed temporal lobe epilepsy. Epilepsia 51:768-772.

Rubino T, Realini N, Castiglioni C, Guidali C, Viganó D, Marras E, Petrosino S, Perletti G, Maccarrone M, Di Marzo V, Parolaro D (2008) Role in anxiety behavior of the endocannabinoid system in the prefrontal cortex. Cereb Cortex 18:1292-1301.

Schubert M, Siegmund H, Pape HC, Albrecht D (2005) Kindling-induced changes in plasticity of the rat amygdala and hippocampus. Learn Mem 12:520-526.
Shoji Y, Tanaka E, Yamamoto S, Maeda H, Higashi H (1998) Mechanisms underlying the enhancement of excitatory synaptic transmission in basolateral amygdala neurons of the kindling rat. J Neurophysiol 80:638-646.

Spagnolo PA, Ramchandani VA, Schwandt ML, Kwako LE, George DT, Mayo LM, Hillard CJ, Heilig M (2016) FAAH gene variation moderates stress response and symptom severity in patients with posttraumatic stress disorder and comorbid alcohol dependence. Alcohol Clin Exp Res 40:2426-2434

Stella N, Schweitzer P, Piomelli D (1997) A second endogenous cannabinoid that modulates long-term potentiation. Nature 388:773-778.

Teskey GC, Corcoran ME (2009) Interictal behavioural comorbidities in a model of epilepsy. In: Encyclopedia of basic epilepsy research (Schwartzkroin P, ed), pp 1254-1260. Oxford: Elsevier.

Teskey GC, Corcoran ME (2015) Kindling. In: International encyclopedia of the social and behavioral sciences (Wright JD, ed), Ed 2, pp 32-35. Oxford: Elsevier.

Wallace MJ, Blair RE, Falenski KW, Martin BR, DeLorenzo RJ (2003) The endogenous cannabinoid system regulates seizure frequency and duration in a model of temporal lobe epilepsy. J Pharmacol Exp Ther 307: 129-137.

Washburn MS, Moises HC (1992) Electrophysiological and morphological properties of rat basolateral amygdaloid neurons in vitro. J Neurosci 12:4066-4079.

Yasmin F, Colangeli R, Morena M, Filipski S, van der Stelt M, Pittman QJ, Hillard CJ, Teskey GC, McEwen BS, Hill MN, Chattarji S (2020) Stressinduced modulation of endocannabinoid signaling leads to delayed strengthening of synaptic connectivity in the amygdala. Proc Natl Acad Sci USA 117:650-655.

Yoshida T, Uchigashima M, Yamasaki M, Katona I, Yamazaki M, Sakimura K, Kano M, Yoshioka M, Watanabe M (2011) Unique inhibitory synapse with particularly rich endocannabinoid signaling machinery on pyramidal neurons in basal amygdaloid nucleus. Proc Natl Acad Sci USA 108:3059-3064.

Zhu PJ, Lovinger DM (2005) Retrograde endocannabinoid signaling in a postsynaptic neuron/synaptic bouton preparation from basolateral amygdala. J Neurosci 25:6199-6207.

Zimmermann T, Bartsch JC, Beer A, Lomazzo E, Guggenhuber S, Lange MD, Bindila L, Pape HC, Lutz B (2019) Impaired anandamide/palmitoylethanolamide signaling in hippocampal glutamatergic neurons alters synaptic plasticity, learning, and emotional responses. Neuropsychopharmacology 44:1377-1388. 